\title{
Papillomavirus E5: the smallest oncoprotein with many functions
}

\author{
Aldo Venuti ${ }^{1}$, Francesca Paolini ${ }^{1}$, Lubna Nasir ${ }^{2}$, Annunziata Corteggio ${ }^{3}$, Sante Roperto ${ }^{3}$, Maria S Campo ${ }^{4}$ and \\ Giuseppe Borzacchiello $3^{3^{*}}$
}

\begin{abstract}
Papillomaviruses (PVs) are established agents of human and animal cancers. They infect cutaneous and mucous epithelia. High Risk (HR) Human PVs (HPVs) are consistently associated with cancer of the uterine cervix, but are also involved in the etiopathogenesis of other cancer types. The early oncoproteins of PVs: E5, E6 and E7 are known to contribute to tumour progression. While the oncogenic activities of E6 and E7 are well characterised, the role of E5 is still rather nebulous. The widespread causal association of PVs with cancer makes their study worthwhile not only in humans but also in animal model systems. The Bovine PV (BPV) system has been the most useful animal model in understanding the oncogenic potential of PVs due to the pivotal role of its E5 oncoprotein in cell transformation. This review will highlight the differences between HPV-16 E5 (16E5) and E5 from other PVs, primarily from BPV. It will discuss the targeting of E5 as a possible therapeutic agent.
\end{abstract}

Keywords: Cell transformation, Growth factor receptors, Immune escape, Oncogene, Papillomaviruses, E5 oncoprotein, Animal models

\section{Introduction}

PVs are established agents of human and animal cancers [1]. They infect cutaneous and mucous epithelia inducing benign tumours which usually regress. Occasionally, the tumours progress to malignancy. Over 120 types of HPVs have been identified so far and among these 15 have been defined as HR HPVs. These are consistently associated with cancer. Genital HPVs are sexually transmitted and HR genital HPVs are a necessary factor in the development of almost all cases of cervical cancer. HPV-16 and -18 are the viruses most frequently associated with cancer of the uterine cervix $(\mathrm{CxCa})$ [2].

$\mathrm{CxCa}$ is the second most common cancer in women worldwide killing about 0.25 million women per year. However, in economically developed countries the rate of $\mathrm{CxCa}$ is dramatically reduced due to screening program based on exfoliative cervical cytology (PAP smears).Vaccines to prevent HR HPV infection are available, although their use should be implemented along with screening programmes to further reduce the

\footnotetext{
* Correspondence: borzacch@unina.it

${ }^{3}$ Department of Pathology and Animal health, University of Naples Federico II, Naples, Italy

Full list of author information is available at the end of the article
}

incidence of such cancer [3]. HR HPVs are also involved in the etiopathogenesis of other anogenital cancer [4]. Furthermore HPV, particularly HR HPV-16 is strongly associated to oral squamous cell carcinoma and other potentially malignant oral lesions [5]. Growing evidence also suggests that HR HPV-16 is involved in the etiopathogenesis of head and neck squamous cell carcinomas, suggesting that HPV vaccines should be also considered for prevention of this type of cancer $[5,6]$. Additionally, HPVs may be involved in the etiopathogenesis of others cancer types, including tumours of the upper respiratory tract, eye, esophagus, non-small-cell lung cancers [7-10]. The presence of HPV-16 has been reported also in colorectal carcinoma [11], breast cancer [12] and urinary bladder carcinoma [13]. Recently, HPV DNA has been associated also with prostatic tumours [14]. The widespread causal association of PVs with cancer makes their study worthwhile not only in humans but also in animal model systems which often provide new and profitable avenues of research [15]. The BPV system has been one of the most useful animal models in understanding the oncogenic potential of PVs. Furthermore, the mechanisms by which BPV induces tumors are an outstanding model to better understand
C Biomed Central

(C) 2011 Venuti et al; licensee BioMed Central Ltd. This is an Open Access article distributed under the terms of the Creative Commons Attribution License (http://creativecommons.org/licenses/by/2.0), which permits unrestricted use, distribution, and reproduction in any medium, provided the original work is properly cited. 
the pathogenesis of other cancer types. The importance of the role of HPV in cancer etiology and development has been recognized by the assignment of the 2008 Nobel Prize for Medicine to Prof. Harald zur Hausen who firstly observed that infection with HPVs is responsible for $\mathrm{CxCa}$ development. The genome of PVs is a double stranded circular DNA roughly divided into three parts: the $\mathrm{E}$ region coding for early proteins (E1E7) responsible for the pathogenicity of the virus; the $L$ region coding for late structural proteins $(\mathrm{L} 1, \mathrm{~L} 2)$ and a non coding region which contains the cis-elements necessary for replication and transcription of the viral genome. Both in vivo and in vitro studies have pointed to E6 and E7 as the main HPV oncogenes, whereas E5 is the major oncogene of BPV. The E6 oncoprotein interacts with the cellular tumour suppressor p53 [16] and directs its degradation [17]. The primary target of the E7 oncoprotein is the retinoblastoma $(\mathrm{Rb})$ proteins, the inactivation of which leads to tumour progression [18]. Both E6 and E7 also interact with many others cellular factors inducing genomic instability, tumour progression and immune evasion [18].

While the oncogenic activities of E6 and E7 are well characterised, the role of E5 is still rather nebulous. However, recent studies have highlighted the important role of this oncoprotein in cell transformation, tumourigenesis and immune modulation, thus implicating E5 in pivotal steps of carcinogenesis. Because of the perceived growing role of E5 in infection establishment and in cell transformation, it is worth considering the most salient features of the oncoprotein. This review will focus on the activities of E5, in particular from HPV-16, and from BPV. Targeting E5 as a possible therapeutic agent will also be briefly discussed.

\section{HPV E5}

\section{E5 and the evolution of HPVs}

HPVs have been classified into five genera (Alpha-, Beta-, Gamma-, Mu- and Nu-PVs), but not all HPV genera code for an E5 protein [19]. For instance $\alpha$ HPVs encode and express E5 but $\beta$ HPVs do not. A phylogenetic analysis of known genital HPV types (derived using a Bayesian methodology, with notation of carcinogenic risk levels assigned by the large case-control study conducted by the International Agency for Research on Cancer [20]), suggested that at least 3 ancestral papillomaviruses are responsible for the current heterogeneous group of genital HPVs. The three major groups that emerged include alpha papillomavirus species and interestingly all carcinogenic types derive from a common ancestor and can code for an E5 protein, whereas the other HPVs either lack a definable E5 ORF (Open Reading Frame) or a translation start codon for E5. As notable exceptions, 10 types which cause benign venereal warts, can also code for an E5 protein. In addition,
$16 \mathrm{E} 5$ variants with the greatest mitogenic activity in vitro [21] are most frequently detected in the population and most commonly associated with cervical lesions.

The HPV E5 ORF itself has been classified into four different groups: alpha, beta, gamma and delta [22], which correlate with different clinical manifestations, in particular with oncogenic potential [23]. Thus, the E5-alpha protein is encoded by HR $\alpha \mathrm{HPV}$, whereas the E5-gamma and E5-delta proteins are encoded by low-risk genital HPVs [24]. The phylogenetic analysis suggests that E5 must give some advantage to the virus expressing it and variants of this protein appear to increase the likelihood of oncogenic transformation following persistent infections. However, the E5 ORF is absent in the genome of many HPVs, such as beta-, gamma- and mu-HPVs, indicating that the protein is not essential for the life cycle of these viruses but rather can give some ADDED VALUE to favour infection and transformation (Figure 1). The HPV E5 ORF is expressed during the early phases of the viral life cycle but only as the fourth ORFs on polycistronic transcripts. Since HPVs are thought to use a leaky ribosome-scanning mechanism to translate proteins from polycistronic mRNAs, little E5 protein is likely to be synthesized from these transcripts. In contrast, on epithelial-cell differentiation, E5 is expressed as the second ORFs of late transcripts. It is therefore likely that E5 is synthesized highly in differentiating suprabasal epithelial cells [25] (Figure 1). In agreement, the BPV-1 E5 protein was detected at a low uniform level in basal layers and at a higher level in the uppermost layers of stratified squamous epithelium in papillomas productively replicating BPV-1 [26]. In addition, E5 was also shown to be expressed in basal and suprabasal layers of BPV4-induced papillomas [27] and of HPV-16 induced cervix lesions [28].

In contrast to the highly transforming BPV-1 E5, the HPV E5 proteins display weak transforming activity in vitro (Table 1). Experiments with HPV-6 provided the first evidence that a HPV E5 protein had transforming activity in mammalian cells, as expression of HPV-6 E5 in established murine fibroblasts lead to anchorage independent growth [29]. Later it was shown that also 16E5 induces anchorage independence, more efficient growth in low serum and tumorigenic transformation of murine keratinocytes and fibroblasts [30-32]. In addition, the acute expression of 16E5 stimulates cellular DNA synthesis in primary human keratinocytes, and in cooperation with E7, induces proliferation of primary rodent cells [33-36]. The transforming activity of E5 from HPV-59 and rhesus papillomavirus has been demonstrated in various cell types and assays [37,38].

\section{Structure and cell interaction}

$16 \mathrm{E} 5$ is 83 amino acid long. The detection of this protein has proved very difficult given its extreme 


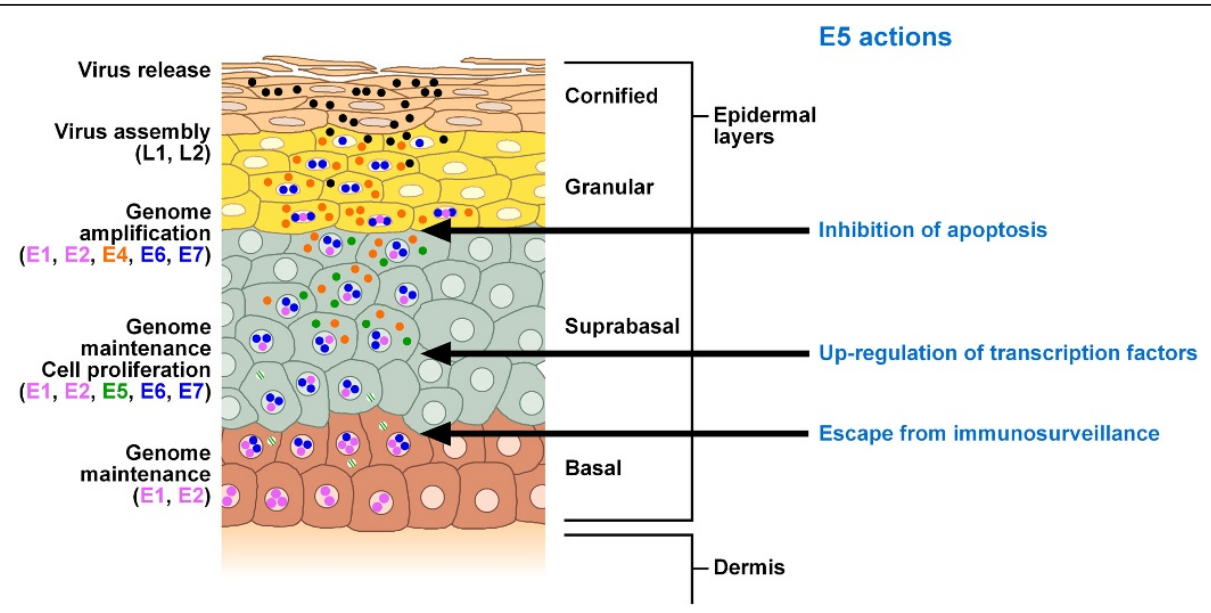

Figure 1 E5 can improve HPV activity by altering host factors controlling the viral replication/persistence. A schematic view of the papillomavirus life cycle highlighting the expression of the HPV genes, which is tightly regulated and strictly linked to epithelial differentiation. E5 could contribute to a successful infection by inducing loss of surface MHC I expression in the infected basal cells preventing presentation of viral antigens to effector T-cells and thus, in addition to other mechanisms of immune avoidance, such as lack of inflammation, contributing to evasion of immune surveillance. Expression of E5 in the basal/suprabasal layers of the epithelium would lead to sustained cell proliferation to favour virus-infected cells, but extinction of its expression in the more superficial layers would permit cell differentiation and virion production. If E5 expression proceeds beyond early lesional stages, keratinocyte differentiation and immunological removal of infected cells would not take place and the lesion would be at greater risk for neoplastic progression. E5 actions on host factors controlling viral replication/persistence are indicated. Dashed dots indicate low levels of E5 gene expression.

hydrophobicity, membrane localisation and very low levels of expression. For these reasons expression of E5 is often inferred from the presence of E5 mRNA. 16E5 has been detected by immunohistochemistry by Chang et al. [28] in low-grade squamous intraepithelial lesions (LSILs), in high-grade SILs, CIN (cervical intraepithelial neoplasia) and paradoxically in cancer lesions although often this gene is deleted during viral integration into the host genome. Amino acid sequence analyses of 16E5 suggest it comprises 3 anchor-like $\alpha$-helices (residues 8$30,37-52$ and 58-76), with only the first being long enough to span a lipid bilayer.

When over-expressed, 16E5 is present in the endoplasmic reticulum (ER), in the nuclear envelope and in the Golgi apparatus (GA) [39], whereas at a more physiological level of expression, as shown in primary human foreskin keratinocytes, it localizes almost exclusively to the ER and to lesser extent to GA and early endosomes [40]. Recently, it was reported that in $\mathrm{HaCaT}$ cells about $10 \%$ of total $16 \mathrm{E} 5$ can localize to plasma membrane with intracellular amino terminus and extracellular carboxyl-terminus. This observation suggests a fusogenic role of $16 \mathrm{E} 5$ with the induction of cell-cell fusion and the formation of binucleated $\mathrm{HaCaT}$ cells [41-43]. In contrast, other authors report the presence of 16E5 protein only in the ER of COS and ectocervical cells in the opposite orientation: intraluminal amino-terminus and cytoplasmic carboxyl-terminus [44]. The cytoplasmic localization of the $\mathrm{C}$ terminus is further strengthened by the reported interaction of 10 amino acids at the $C$ terminus of $16 \mathrm{E} 5$ with karyopherin $\beta 3$ (KNB3) [45], an abundant cellular protein localized mainly in the cytoplasm [46,47]. An explanation for these contrasting data is the possible presence of 16E5 in the plasma membrane as a consequence of the overexpression of 16E5 by the adenovirus vector system used in HaCaT cells. In agreement, when BPV-1 E5 is expressed at very high levels, such as in baculovirusinfected cells, it is detectable on the plasma membrane in addition to the ER and GA [48].

16E5 self-associates in vitro [49] and in vivo [40,50] and this oligomerization takes part mostly by hydrophobic interaction. The reported disulfide bonding [40] appears less likely because models of 16E5 membrane topology predict the localization of all six cysteine residues within the lipid bilayer $[21,51]$ rendering cysteine dimerization more difficult.

\section{E5 and cell transformation}

E5 interacts with a number of cellular proteins and these interactions are deemed important for the biological activity of the protein in cell transformation and evasion of the immune response. Thus the first transmembrane domain of 16E5 and HPV-31E5 interacts directly with the heavy chain component of the MHC I (Major Histocompatibility Complex class I) via the leucine pairs present in this region; interestingly this same transmembrane domain interacts with a chaperone 
Table 1 Comparison of function of HPV E5 proteins with BPV E5 proteins

\begin{tabular}{|c|c|c|c|c|}
\hline E5 & LR HPV-6 & HR HPV-16 & BPV-1 & BPV-4 \\
\hline FF & n.e. & - & + & + \\
\hline SI & n.e. & + & + & + \\
\hline $\mathrm{Al}$ & + & + & + & + \\
\hline Koilocytosis & + & + & n.e. & n.e. \\
\hline PDGF $\beta R$ activation & n.e. & - & + & n.e. \\
\hline$\overline{\text { EGF-R activation }}$ & + & + & + & n.e. \\
\hline V-ATPase binding & + & + & + & + \\
\hline Gap-j inhibition & n.e. & + & + & + \\
\hline PI3-K activation & n.e. & + & + & n.e. \\
\hline c-Src activation & - & - & + & + \\
\hline Cyclin-cdk2 activation & n.e. & + & + & ++ \\
\hline MHC I down-regulation & + & + & + & + \\
\hline KN $\beta 3$ binding & n.e. & + & n.e. & n.e. \\
\hline TRAIL pathway inhibition & n.e. & + & n.e. & n.e. \\
\hline MAPK activation & + & + & - & n.e. \\
\hline ETA activation & n.e. & + & n.e. & n.e. \\
\hline PGE2 R expression & n.e. & + & n.e. & n.e. \\
\hline Cellular zinc imbalance & n.e. & + & n.e. & n.e. \\
\hline ER Stress pathway inhibition & - & + & n.e. & n.e. \\
\hline Cellular fusion & - & + & n.e. & n.e. \\
\hline P21 inibition & + & + & n.e. & n.e. \\
\hline
\end{tabular}

FF: focus formation; SI: serum independence; Al: anchorage independence. +: presence of function; -: absence of function; n.e.: not established.

of MHC I, Bap31 [52,53]. A region within the second helix (residues 41-54) may be the binding site for the 16 $\mathrm{kDa}$ pore sub-unit of vacuolar-ATPase (V-ATPase) [54], although others claim this is located between residues 54-78 [55].

E5 is a weak transforming protein in vitro and its effects are seen best when in co-operation with the other viral oncoproteins: 16E5 together with E6 can induce the formation of koilocytes, large cells with cleared cytoplasm and pyknotic nuclei with inconspicuous nucleoli, a well known morphological marker of HPV infection [56]. The development of koilocytotic vacuoles may be linked to the E5-induced relocalization of calpactin I to the perinuclear region promoting perinuclear membrane fusion [57]. Hu et al. [43] confirmed previous reports describing the oncogenic capacity of $16 \mathrm{E} 5[30,58]$ and offered mechanistic insights into how E5 expression brings about morphological changes in the cervical epithelium. Further, by identifying endoreplication as the mechanism by which the aberrant nuclei form and increased DNA synthesis arises, there is now a biological process that can be targeted to inhibit oncogenesis [43]. Fusogenic 16E5 is expressed on the plasma membrane of cells and both cells must express E5 for cell-cell fusion to occur, indicating that E5 cannot induce cell-cell fusion through an interaction with another protein (receptor) on a neighbouring cell, but rather forms E5-E5 dimers or complexes containing at least two 16E5 molecules. These findings provide important insight into how the fusogenic process is mediated [41].

E5 of HR HPV by itself can induce morphological and chromosomal changes that frequently accompany the progression of normal cells to cancerous cells. Increased nuclear size, increased DNA content and tetraploidy are characteristic of LSIL $[59,60]$. All of these morphological changes have been detected in cell expressing 16E5 and, in particular, the aberrant nuclei formation seems to be due to endoreplication rather than a consequence of cell-cell fusion and failed cytokinesis [43]. Many of these changes are criteria used in the clinical detection of cervical cancer precursors in screening Pap tests [61]. Other morphological changes, such as the presence of binucleated cells, increased DNA content and polyploidy [62], are not used in the diagnosis of precancerous lesions despite being less subjective because they require larger amounts of material, time, and expenses.

\section{HPV E5 interaction with host cell}

HPVs infect stratified epithelia, and their whole life cycle is inextricably linked to keratinocyte differentiation and, in order to establish a persistent infection, HPVs have evolved to overcome many "obstacles":

a) The stratified epithelium is associated with continuous cellular turnover and desquamation of the terminally differentiated keratinocytes, thus maintenance of the papillomavirus within the tissue requires the infection of basal epithelial cells and the propagation of these infected cells.

b) Papillomaviruses use the cellular machinery for their replication and need to maintain cell division together with a delayed but not completely inhibited differentiation. HPV infected keratinocytes with imbalanced DNA synthesis/differentiation are forced to apoptosis by the cellular control mechanism.

c) To establish persistent infection HPV must fight or evade immune-surveillance.

It is clear that the timely and epithelial differentiationdependent expression of all $\mathrm{E}$ proteins is essential to favour viral replication and in turn to overcome the above mentioned obstacles. The "E5 added value" will be highlighted in the following paragraphs.

\section{E5, growth factors and cell cycling}

HPV infection is thought to take place when epithelial basal cells are directly exposed to the virus during microinjuries [63]. Infection of epithelial stem cells, which have the capacity for self-renewal, can ensure 
long term maintenance of the viral genome. During the productive stage of the HPV life cycle, the early viral proteins are expressed, maintaining 50-100 copies of episomal DNA per cell by synchronous replication with host cell DNA [64-66]. The demonstrated ability of $16 \mathrm{E} 5$ to enhance ligand-dependent activation of the EGF-R [56,58-60] (Figure 2) and to stimulate EGFdependent proliferation of cultured human keratinocytes $[33,35,58]$ suggests that 16 E5 may play a major role in expanding populations of HPV-16-infected basal keratinocytes in vivo by enhancing ligand-dependent EGF-R activation. Confirmation of this E5 activity comes from a study on 16E5 transgenic mice showing that functional EGF-R is required for the induction of epidermal hyperplasia and formation of spontaneous skin tumours [67]. $16 \mathrm{E} 5$ oncoprotein binds and inhibits the activity of the $16 \mathrm{kDa}$ subunit of V-ATPase, altering the endosomal acidification and degradation of EGF-R [34,68] thus enhancing its recycling to the plasma membrane. 16E5 can also delay EGF-R degradation by interfering with membrane trafficking and the fusion of early and late endosomes [69]. Recently, 16E5 was shown to form a complex with $\mathrm{KN} \beta 3$ which is localized mainly in the cytoplasm near the nuclear envelope [45]. It has been suggested that a KN $33 / 16 \mathrm{E} 5$ complex plays an important role in vesicle trafficking, reinforcing the hypothesis that E5 has a central role in altering protein trafficking inside the cell. The EGF-R signalling pathway can be activated by $16 \mathrm{E} 5$ through either EGF-dependent or EGF-independent processes. 16E5 activates mitogenactivated protein kinase (MAPK) p38 and ERK1/2 in human keratinocytes in an EGF-independent manner [70]. Two different pathways, a receptor tyrosin kinasemediated pathway and a protein kinase $C$ (PKC)-dependent pathway, are involved in the MAPK activation $[71,72]$ which increases the transcription of $c$-fos and $c$ jun $[33,73,74]$, forcing the cells through the cell cycle and stimulating transcription of the viral oncogenes E6 and E7. In contrast with EGF-R data, less is know about the role of the interaction of 16E5 with other ErbB family members such as ErbB2 or ErbB4 receptor [28,75-77].

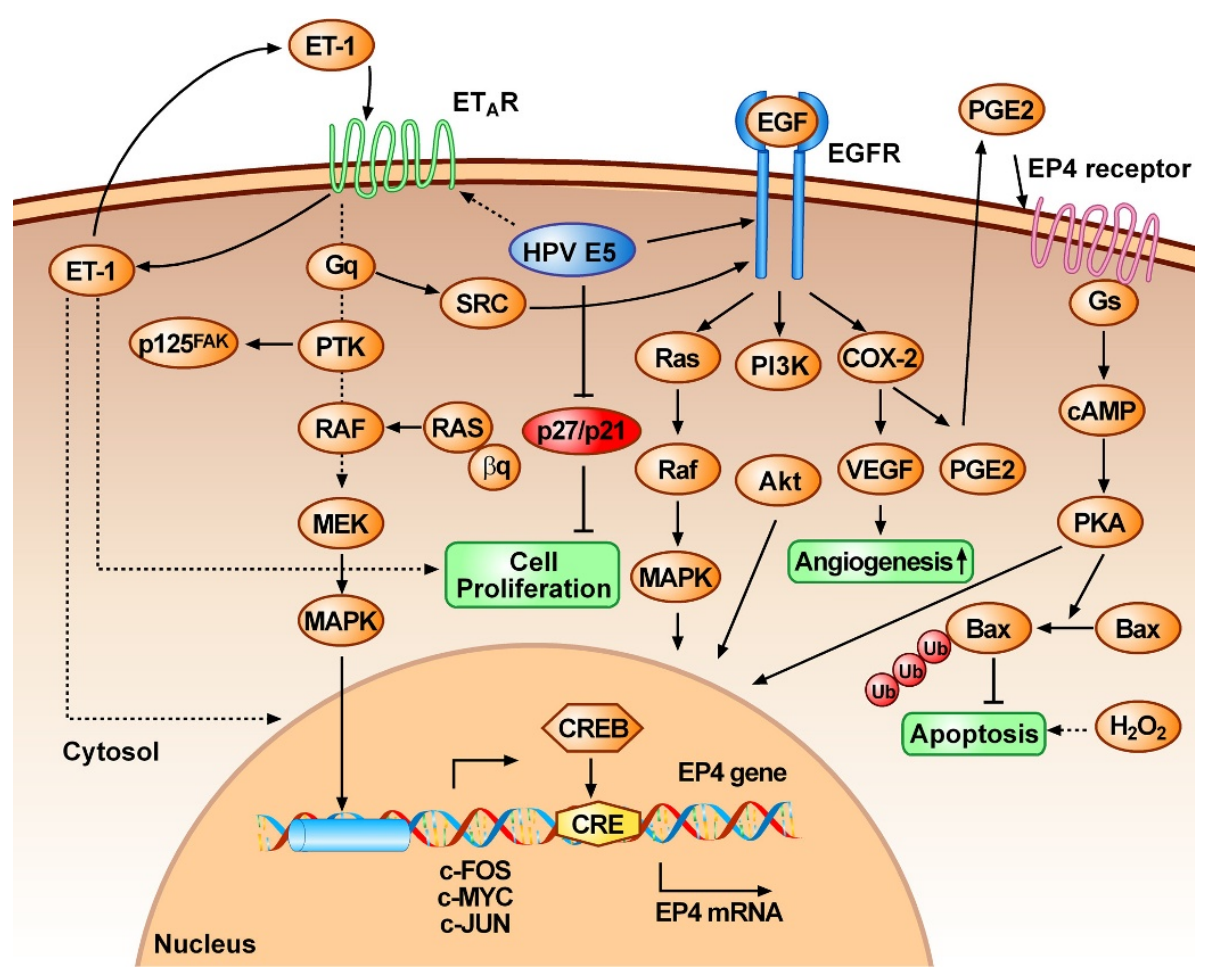

Figure 2 HPV 16 E5 enhances growth factor signalling pathways. Activation of EGF-R and the downstream Ras-Raf-MAP kinase pathway or PI3K-Akt pathway leads to altered cell proliferation, angiogenesis, and anti-apoptosis. The last two functions are further enhanced by the E5induced upregulation of COX-2 expression. COX-2 expression inhibits hydrogen peroxide-induced apoptosis and induces PGE2 secretion that activates EP4 receptor. This, in turn, causes CAMP production, activating PKA; PKA contributes to E5-induced expression of EP4 by enhancing CREB binding to variant CRE of the EP4 promoter. PKA influences also apoptosis through the ubiquitin-proteasome degradation of BAX. Finally, E5 protein enhances cell proliferation through downregulation of tumor suppressor p21/p27 and through up-regulation of G protein-coupled endothelin receptor $\left(\mathrm{ET}_{\mathrm{A}}\right) / \mathrm{ET1}$ autocrine loop. Dotted arrow shafts indicate uncertain pathways. The possible cross-talking between ETAR and EGFR pathway through Src protein is also indicated. 
$16 \mathrm{E} 5$ is also capable of interacting with, and enhancing the signalling of, different classes of growth factor receptors like the $G$ protein-coupled endothelin receptor $\left(\mathrm{ET}_{\mathrm{A}}\right)$ [36]. In growth factor-starved keratinocytes 16E5 enhances the mitogenic activity of endothelin-1 (ET-1) the specific ligand of $\mathrm{ET}_{\mathrm{A}}$ (Figure 2). Interestingly it was reported that the mitogenic activity of ET-1 may lead to the chronic stimulation of keratinocyte proliferation observed in psoriasis, an inflammatory/proliferative disorder of the skin, suggesting an important role for ET-1 in epithelial proliferation [78]. Furthermore cross-talking between $\mathrm{ET}_{\mathrm{A}} \mathrm{R}$ and EGF-R pathways would have an amplifying effect on cell proliferation [79].

In contrast to the activation of EGF-R, 16E5 can down-modulate the keratinocyte growth factor receptor/ fibroblast growth factor receptor $2 \mathrm{~b}$ (KGF-R/FGF-R2b), through reduction of transcripts and protein with alteration of the receptor endocytic trafficking. This causes a decrease in the growth response to the receptor ligands, suggesting that 16E5 might have a role on HPV infection by perturbing the KGFR-mediated physiological behaviour of confluent keratinocytes committed to differentiation [80]. Thus, 16E5 could exert two opposite effects, both related to virus replication: (a) increasing the growth of the most basal undifferentiated cells by up-regulating the EGF-R pathway and (b) decreasing the physiological proliferation/differentiation of the suprabasal keratinocytes by down-modulation of KGFR expression and signalling.

16E5 can also down-regulate the expression of tumour suppressor p21 and p27, both of which are cyclindependent protein kinase inhibitors (CKIs), thus causing cell cycle progression and DNA synthesis (S-phase) (Figure 2). The p $21^{\mathrm{Wafl} / \mathrm{Sdil} / \mathrm{Cipl}}$ down-regulation is at transcriptional level [81] whereas that of $\mathrm{p} 27^{\mathrm{Kip} 1}$, one of the most abundant CKIs, is through reduction of the halflife of $\mathrm{p} 27^{\mathrm{Kip} 1}$ protein [82].

Other biological activities of $16 \mathrm{E} 5$ contribute to the proliferation of the infected cells, such as the interference with cell-cell communication and alteration of adherence and cell motility. The ability of $16 \mathrm{E} 5$ to inhibit gap junction-mediated communication between epithelial cells in monolayer [83] and in raft cultures [84] by interfering with connexin 43 may render the transformed cells more insensitive to homeostatic growth control signals from adjacent normal cells.

\section{E5 and apoptosis}

Due to the integration of HR HPV genome during malignant progression, the E5 gene is not expressed in cervical tumours but both 16/18 E5 mRNA and protein have been detected in anogenital LSIL $[85,86]$ supporting the possibility that E5 plays a role in early steps of $\mathrm{HPV}$ infection to protect infected cells from apoptosis.
Indeed, it has been proposed that inhibition of death receptor-mediated apoptosis in human keratinocytes, needed to prevent apoptosis at early stages of viral infection, is a primary function of the HR HPV E5 protein. 16E5 impairs tumor necrosis factor ligand (FasL) and Tumor necrosis factor-related apoptosis-inducing ligand (TRAIL)-mediated apoptosis in $\mathrm{HaCaT}$ cells by: (a) downregulating the total amount of Fas receptor and reducing Fas surface location; and (b) altering the formation of Death-Inducing Signalling Complex (DISC) triggered by TRAIL [87]. Raft cultures of 16E5-expressing keratinocytes were completely protected from FasLor TRAIL-induced cell death [88]. Likewise, when UV radiation was used to induce stress, E5-expressing human keratinocytes were protected from apoptosis [89]. In contrast, 16E5 sensitizes human keratinocytes to apoptosis induced by osmotic stress, perhaps due to cell membrane modifications caused by this strongly hydrophobic molecule [90].

\section{E5 and ER stress pathway}

The presence of viral proteins may activate cellular defence mechanisms and in particular the ER stress response. 16E5 can suppress three key proteins of the ER stress pathway: cyclooxygenase-2 (COX-2), XBP-1 and IRE1a. As it was suggested for other viruses, the down-regulation of these proteins can favour viral persistence [91] which is a major contributory factor to the development of cancer by high-risk HPVs [92]. The inhibition of the ER stress pathway by E5 seems to be limited to the high risk types (Table 1); HPV-6b E5 is unable to alter XBP-1 [93] and increased levels of COX2 were reported in recurrent respiratory papillomatosis (RRP) lesions caused by low-risk HPV type $6 \mathrm{~b}$ and 11 $[94,95]$. 16E5 is also able to lower COX-2 expression in cells co-expressing E6/E7, suggesting that it might exert similar activity during viral replication.

However, in different cell systems and clinical conditions the same viral early genes seem to exert opposite effects such as the induction of COX-2 expression in spontaneously immortalized $\mathrm{HaCaT}$ and cervical cancer lines C33A and $\mathrm{SiHa}[96,97]$. It is possible that the different cell origin, immortalization and transformation status, and the relative expression of the HPV early proteins account for these contrasting data. Nevertheless the reported consistent down-regulation of ER stress response genes by 16E5 in primary genital keratinocytes leads to speculation that this ER stress pathway inhibition is an event favourable to viral replication and persistence [98].

Finally, 16E5 may induce expression of one of the Prostaglandin E2 $\left(\mathrm{PGE}_{2}\right)$ receptor in cervical cancer cells by stimulating the binding of CREB to a variant CRE site in the promoter of EP4 gene [99] (Figure 2). EP4 
pathway activates protein-kinase A which mediates ubiquitin-proteasome-mediated Bax degradation, inducing antiapoptotic effects. Activation of EP4 by 16 E5 increases anchorage-independent colony formation and vascular endothelial growth factor (VEGF) expression, leading to speculation that al least in some tumours E5 is involved in tumour growth, angiogenesis and metastasis by inducing inflammatory cell signalling pathways.

\section{HPV E5 and immune evasion}

Cervical carcinogenesis is a multi-step process which starts with viral infection; one of the steps is persistence of viral infection. At least three major factors may favour papillomavirus persistence: the virus life cycle takes place away from dermal immune cells [100], the virus does not cause cell lysis and therefore no or weak inflammatory response [100], and, finally, the viral proteins actively fight the immune response [101]. The E6 and E7 proteins play an important role in this fight but, once again, the E5 protein seems to add help to the virus by down-regulating MHC/HLA class I. MHC class $\mathrm{I}$ is much reduced on the cell surface and accumulates in the GA in cells expressing 16E5 [102]. The arrest of $\mathrm{MHC}$ class I in the GA is due to E5-induced alkalinisation of the endomembrane compartments [103], following 16E5-16 k subunit $\mathrm{c}$ interaction, and to the direct interaction of $\mathrm{E} 5$ with the heavy chain of the MHC class I complex [53,104]. These conclusions have been reached in cultured $\mathrm{HaCaT}$ cells and W12 cell line, and in vivo in the bovine model [105]. The functional effect of the decreased expression of HLA is a reduction of the recognition by $\mathrm{CD}^{+} \mathrm{T}$ cells in vitro [106].

Furthermore consistent with its role in the alkalinization of endosomes, $16 \mathrm{E} 5$ can prevent the endosomal breakdown of the invariant chain, a chaperone important in the maturation of HLA class II, leading to inhibition of expression of surface HLA class II [107].

Inhibition of HLA class I transport by $16 \mathrm{E} 5$, in contrast to inhibition by BPV E5, is reversible by interferon (IFN) treatment. IFN is sufficient to overcome the inhibitory effect on $\mathrm{MHC}$ transport in presence of low levels of 16E5. However, in oncogenic HPV infections, E6 and E7 can inhibit the type I IFN pathway [108-110], thus preventing the IFN-mediated release of E5-induced blockage of HLA class I traffic.

Although an efficient mechanism to avoid cytoxic $\mathrm{T}$ lymphocytes (CTL)-mediated immune clearance, the reduction or absence of surface $\mathrm{MHC}$ class I renders cells more susceptible to Natural Killer (NK) cell attack. Human NK cells express multiple receptors that interact with HLA class I molecules, including killer cell immunoglobulin-like receptors (KIRs) that predominantly recognize classical HLA class I, including HLA-C, and the $C$ type lectin superfamily of receptors that specifically interact with the nonclassical class I molecule HLA-E. Recognition of the class I molecules by their inhibitory receptors inhibits NK-mediated cell lysis, which would occur in the absence of HLA-C/E. Thus to efficiently evade immunosurveillance, HPV has to selectively down-regulates the HLA class I molecules. Indeed 16E5 selectively inhibits surface expression of HLA-A and HLA-B without affecting either synthesis or transport to the cell surface of HLA-C/E [97,100,101]. In this way HPV-16 is potentially capable of avoiding both CTL and NK cell killing.

The bridging of innate and adaptive immune responses can also be affected by E5 via the inhibition of CD1d-mediated cytokine production that would otherwise occurs upon interaction between cell surface CD1d and iNKT cells [111].

It was reported that interactions between 16E5 and calnexin interfere with modification of HLA class I HCs and results in heavy-chain retention in the ER [51]. Since the synthetic pathways for CD1d and HLA class I HCs are similar, this E5-calnexin interaction may alter CD1d trafficking. Indeed, interactions between 16E5 and calnexin do not appear to interrupt all of the functions of calnexin, but just enough to coopt the cellular cytosolic proteolytic pathway and degrade CD1d. Thus E5 inhibits the CD1d-mediated innate and adaptive immune pathways early in HPV infection.

Finally, the reported novel association of HPV-16 and HPV-31 E5 with Bap31 and A4 can also have an effect on immune escape [52]. Bap31 is a chaperone involved in quality control of, for instance, MHC molecules; A4 is a putative ion channel protein of the endoplasmic reticulum. E5 and Bap31 physically interact and colocalise in perinuclear structures and it was demonstrated that this binding correlates with the ability to retain the proliferative capacity of infected keratinocytes following differentiation. E5 also binds and colocalises with A4 independently of Bap31, however the biological significance of this interaction remains to be established. Interestingly 16E5 first transmembrane domain which binds MHC heavy chain shows homology with the third transmembrane domain of Bap31 [53]. Therefore it is possible that membrane-bound 16E5 displaces Bap31 from MHC I, maybe taking advantage of its own interaction with Bap31, and thus retains MHC I in the ER/ GA.

Thus immune escape mediated by E5 seems to be a complex process, perhaps evolved to impact on different pathways regulating the intracellular trafficking of immunosurveillance molecules by general not-specific mechanisms, such as endosomal alkalization, and specific ones, such as binding to MHC I heavy chain and chaperones such as calnexin, invariant chain or Bap31. It remains to be seen if E5 expression causes immune 
escape also in vivo. An inverse correlation exists between expression of $16 \mathrm{E} 5$ and presence of surface MHC I in the W12 keratinocyte line derived from a CIN I biopsy [106], and in a small panel of naturally occurring CIN lesions (Campo, unpublished observations). Additionally, again in a limited number of samples, an association has been reported between decreased CD1d immunoreactivity and progression of cervical neoplastic lesions with statistical significance $(P$ $=0.0001)$ [111].

\section{Cell transformation pathways alternative to E5}

Beta-HPVs do not code for an E5 protein. Considering the ubiquitous presence of beta-HPVs in the healthy population with almost no associated pathologies, the lack of E5 ORF in these HPV could represent a factor hampering the fully replicative cycle of these viruses. Moreover, some beta-HPVs are detected together with HPV-3 or related genotypes [112], and such a co-detection with E5-encoding HPVs suggests that beta-HPVs benefit from E5 delivered by the co-infecting HPV [113]. In human pathology there is a rare, autosomal recessive genodermatosis associated with a high risk of skin carcinoma, Epidermodysplasia Verruciformis (EV), characterized by abnormal susceptibility to infection by beta HPVs. Genetic analysis led to the identification of two adjacent genes (EVER1 and EVER2), the mutation of which segregates with the disease [114]. This extraordinarily high sensitivity to infections by cutaneous betaHPVs in otherwise-healthy individuals carrying a mutation in one of the EVER genes suggests that in humans a natural EVER-based barrier exists, which protects the host from PVs. The EVER proteins are crucial for the functional integrity of the EVER/ZnT-1 complex $[115,116]$ responsible for maintaining a low level of free zinc, modulating the activity of the AP-1 transcription factors needed for viral genome expression. It has been proposed that a cellular zinc imbalance constitutes an important, perhaps even a crucial, step in the HPV life cycle. It seems that breaking the barrier to cellular zinc balance is an important element of the pathogenesis of both alpha- and beta-HPVs, and the main difference between these two groups would be a mechanism employed to achieve the same goal. Beta-HPVs are defective for this zinc imbalance, an important growthpromoting function performed by E5 of alpha-HPVs, and inactivation of EVER proteins may compensate for the missing viral function [117]. Indeed the transmembrane viral 16E5 and cellular EVER proteins interact both with the zinc transporter ZnT1, and are likely to modulate zinc homeostasis $[115,117]$. The disruption of the cellular zinc-transporting complex achieved during the long co-evolution of HPV and the human species by two completely unrelated strategies underlines the general importance of the cellular zinc (im)balance in the papillomavirus life cycle and the central role played by E5.

In the absence of E5, beta-papillomaviruses have evolved a mechanism to escape immunosurveillance independent of E5. Indeed the E6 and E7 oncoproteins of cutaneous HPV-38 interfere with the interferon pathway. Expression of the two viral proteins in $\mathrm{HaCaT}$ keratinocytes led to a decrease of MHC I levels. This down-regulation was associated with a reduction of expression of MHC I heavy chain, of the peptide chaperone TAP and of the STAT-1 downstream effector IRF-1 [118]. Thus, at least for some (high risk?) beta papillomavirus other E5-unrelated mechanisms take part in the process of viral replication and avoidance of immune control.

\section{HPV E5 and carcinogenesis}

HPV E5 proteins are not thought to play a role in the later steps of malignant progression because in high-risk $\mathrm{HPV}$ infections that progress to cancer the viral DNA typically integrates into the host genome often resulting in the loss of the E2 and E5 genes [65]. However in contrast to other high-risk HPVs, HPV-16 DNA can exist in integrated, episomal or integrated and episomal form in malignant lesions of the cervix. In one study about $60 \%$ of HPV-16-positive cervical cancer expressed the 16E5 protein [28] and recent reports suggest that these tumours with episomal HPV-16 may have a more aggressive behaviour (Venuti, unpublished data). Nevertheless, the fact that a substantial proportion of the tumours do not express E5 indicates that the protein is not essential for HPV-16 mediated tumour progression.

Although 16E5 may not contribute to malignant progression, there is evidence that if E5 expression proceeds beyond early lesional stages, keratinocyte differentiation and immunological removal of infected cells does not take place increasing the likelihood of subsequent oncogenic transformation.

The presence of an E5 gene in all HR HPVs [23] and the detection of E5 variants with higher codon usage in high grade lesions [119] point to an important role of E5 during PV-induced pathogenesis. This assumption is further strengthen by studies on transgenic animals: (a) Transgenic mice expressing only HPV-16 E6 and E7 oncogenes in the basal epithelium develop fewer tumours than those arising in transgenic mice expressing HPV-16 E5, E6 and E7 genes [120] (b) Mice transgenic for 16E5 (without HPV 16 E6 and E7) develop skin tumours with high frequency [67].

One or more of the demonstrated biological activities of $16 \mathrm{E} 5$ may be responsible for early post-infection events enhancing the probability of subsequent carcinogenesis. Indeed viral persistence is considered to be an 
important factor in the neoplastic progression of a premalignant lesion [65]. The 16E5-induced down regulation of MCH I [104] and MHC II [107], resulting in the infected cell evading immunosurveillance, may increase the duration and size of the HPV infection raising the probability that some infected cells will become transformed. The expansion of infected cells may also be favoured by 16E5-induced DNA synthesis in differentiating keratinocytes [121] and by 16E5-enhanced liganddependent activation of EGF-R [56,58-60]. Furthermore the ability of $16 E 5$ to inhibit gap-junction-mediated intercellular communication via connexin 43 interaction may render the infected cells more insensitive to homeostatic growth control signals from adjacent, noninfected cells [83,84]. 16E5 induction of cell fusion may represent another critical event in the early stage of HPV-associated cervical cancer [41-43]. Thus, HR HPVs E5 is involved in the very early stage of carcinogenesis by prolonging the life and expanding the pool of the infected cells from which cancer may arise as a stochastic event. Finally E5 can be also involved in negative selection of cells harboring episomal virus and in turn favoring the selection of cells with integrated virus. Episome loss, associated with induction of antiviral response genes, could be a key event in the spontaneous selection of cervical keratinocytes containing integrated HPV16. Microarray analysis showed that episome loss was closely associated with endogenous activation of antiviral response genes that are also inducible by type I IFN pathway [122]. Recently this activation of the antiviral state was shown to be induced by 16E5 through the stimulation of IRF- 1 and IFN- $\beta$ [123]. In this scenario cervical carcinogenesis requires not only HR HPV integration, but also loss of inhibitory (E2 expression) episomes by the E5-induced establishment of an antiviral state that may accelerate episomal clearance.

\section{BPV E5}

BPV E5 is the best characterized of the E5 proteins and has provided the blueprint for investigations into HPV E5. E5 is the major BPV oncoprotein, only 44 amino acid in BPV type 1 (BPV-1) and 42 in BPV type 4 (BPV4) [124-127]. Both proteins can be divided into two distinct domain: an amino-terminal domain which makes up the majority of the protein and consists of strongly hydrophobic leucine-rich membrane-spanning amino acid residues with a single hydrophilic amino acid at position 17 (glutamine in BPV-1 E5 and asparagine in BPV-4 E5), and a short hydrophilic carboxyl-terminal domain[125,128]. Both E5 proteins localize in the endomembrane compartments of the GA, ER and plasma membrane. It has been suggested for BPV-1 E5 that helix-helix hydrophobic contacts within the TM domain play a critical role in functional dimer assembly and that the cystein-containing motif functions as additional dimer stabilization [129-131].

\section{Cell transformation by BPV E5}

Despite their structural similarity, BPV-1 and BPV-4 E5 differ in the ways they achieve cell transformation, likely reflecting the different origin of the cells hosting the two viruses. BPV-1 infects fibroblasts and skin keratinocytes giving rise to fibropapillomas, whereas BPV-4 infects solely the epithelial cells of the mucous epithelium of the upper gastrointestinal tract [132]. Thus, while expression of BPV-1 E5 by itself is sufficient to fully transform mouse and primary human fibroblast cells $[133,134]$, BPV-4 E5 contributes to the transformed phenotype of primary cells by conferring anchorage independent growth, growth in low serum, focus formation and increased cell motility but only in the presence of the other viral oncoproteins, resembling in this respect 16E5 (Table 1) $[127,135,136]$. For both proteins the hydrophobic domain, the hydrophilic residues at position 17 and the hydrophilic C-terminal tail are critical for their transforming activities [135,137].

BPV-1 E5 induces tumourigenic cell transformation by strongly and specifically binding to its cellular target, Platelet Derived Growth Factor Receptor $\beta$ receptor (PDGF $\beta-R)$ tyrosine kinase in a ligand-independent manner [138-141]. The PDGF $\beta-\mathrm{R}$ is a transmembrane protein which is normally activated by binding of its ligand PDGF. BPV-1 E5 can bind as a dimer to two monomers of the PDGF $\beta-R[140,142,143]$, inducing receptor dimerisation which in turn causes trans-phosphyorylation of specific tyrosine kinase residues within the cytoplasmic domain of the receptor resulting in mitogenic signalling [144]. Studies using PDGF $\beta-R$ kinase inhibitors show that maintenance of transformation by BPV-1 E5 requires sustained PDGF $\beta$ - $R$ activation $[145,146]$.

BPV-1 E5 interacts with the PDGF $\beta$ - $R$ via its transmembrane domain $[141,142,147]$, unlike the natural ligand PDGF which binds the receptor via its ligand binding domain Extensive characterisation of E5 demonstrates that there are essentially four residues important for PDGF $\beta-R$ binding and activation. These are the transmembrane glutamine (Gln17) important for both dimerisation of E5 and for its interaction with PDGF $\beta$ $\mathrm{R}$; the aspartic acid (Asp 33) residue at the juxtamembrane region which provides a negative charge required for receptor interaction and two terminal cysteine residues (Cys37, Cys39) essential for homodimerisation of E5 $[125,137,145,148,149]$. Interestingly, these four residues are conserved among the E5 proteins of fibropapillomaviruses [150] whereas other residues within the transmembrane region are less well conserved. Mutagenesis studies have demonstrated that BPV-1 E5 can 
tolerate a surprising number of mutations and that the maintenance of the hydrophobic nature of E5 and the conserved residues is enough to confer transforming activity [151-155].

Mutational analyses of the receptor itself have identified key residues important for function. The PDGF $\beta-R$ is as single span type I transmembrane receptor with three domains: an amino terminal domain which binds its receptor, a short membrane spanning region and an intracellular kinase domain. Two residues appear to be important for E5 interaction and transformation activity: a threonine 513 in the transmembrane domain is required for $\mathrm{H}$ bonding with $\mathrm{Gln} 17$ residue of the $\mathrm{E} 5$ protein and lysine at 499 in the juxtamembrane region with Asp33 in the E5 protein [156-158]. An important feature of BPV-1 E5 mediated PDGF $\beta-R$ activation is that activation occurs independently of PDGF since E5 can constitutively activate PDGF $\beta$-R deletion mutants that lack the extracellular ligand-binding domain [141,159].

The interaction between BPV-1 E5 and PDGF $\beta-R$ is highly specific. At physiological levels, E5 is able to interact with PDGF $\beta-R$ but not with other tyrosine kinase receptors including insulin receptors, basic fibroblast growth factor receptor or insulin-like growth factor receptors, however at higher levels E5 can interact with additional receptors $[140,144]$. E5 cannot bind the PDGF $\alpha$ receptor, a closely related receptor to the PDGF $\beta$ - R whilst both of these receptors can be activated by PDGF [140-144]. The specificity is thought to be conferred by the transmembrane domain [159].

Most of the studies on BPV E5 and PDGF $\beta$ - R activation have been performed in vitro. Borzacchiello et al (2006) have shown that BPV-2 E5 interacts with and activates the PDGF $\beta-\mathrm{R}$ in vivo in bovine urinary bladder cancers (Figure 3). Moreover, the binding of E5 to $P D G F \beta-R$ induces the activation of different signal transduction pathways: PDGF $\beta-\mathrm{R}$ and phosphoinositide 3 kinase (PI3K) physically interact as do PDGF $\beta-R$ and the Grb2-Sos complex. PI3K-Akt and Grb2-Sos-Ras signals are all potentiated in cancer, but, as in in vitro models, the levels of Erk and Mek proteins are not significantly overexpressed [160-162] (Figure 4). BPV E5 is able to activate c-src, a non receptor tyr kinase, but not the closely related c-Fyn and PI3K [163]. The activation of the latter is necessary but not sufficient to induce cell transformation independently of PDGF $\beta$ - $R$ signalling $[163,164]$. Unlike BPV-1 E5, BPV-4 E5 induces transformation of established cells independently from the constitutive activation of tyrosine kinase growth receptors (Table 1) [165]. Cell transformation by BPV-4 E5 (either of established cells by itself or of primary cells in cooperation with other viral oncoproteins) is achieved through transactivation of the cyclin A gene promoter, increased cyclin A expression and cyclin A-associated kinase activity, and inhibition of the negative regulator of cell cycle, p27 ${ }^{\text {Kip1 }}$ [135,166-168]. Mutational analyses of BPV-4 E5 have demonstrate that, as is the case for BPV-1 E5, the residue at position 17 and the hydrophilic C-terminal tail are critical for its transforming activities [135]. Thus both mutation of Asp 17 and deletion of the C-terminus hydrophilic domain completely abrogate cell transformation and E5 ability to activate the cyclin A pathway [135].

\section{Down-regulation of $\mathrm{MHC}$ expression}

The down-regulation of surface MHC I and retention of the MHC I complex in the GA were first shown in cells expressing BPV-4 E5 [169] and then confirmed for other E5 proteins both from BPV and HPV. BPV E5 interferes with MHC I biosynthesis at multiple steps: transcriptional inhibition of the MHC class I heavy chain gene, degradation of the heavy chain and physical interaction with any residual heavy chain $[169,170]$. Only the physical interaction with heavy chain is shared with 16E5 [99]. Moreover, in the case of BPV-4 E5 the down-regulation of surface MHC I is irreversible, as interferon cannot restore the transport of the MHC I complex to the cell surface [128], while this is not the case for 16E5. This may reflect the fact that E5 is a "stronger" protein in BPV than in HPV.

In any event, the finding of MHC down-regulation by E5 has proved of great importance since it defined a new biological activity shared by both BPV and HPV E5 (Table 1), which allows the infected cell not to be effectively recognised by cytotoxic CTL [106].

\section{BPV E5: other biological activities}

BPV E5 interacts with the $16 \mathrm{kDa}$ protein, a component of the V-ATPase $[147,171]$. In the case of BPV-1 E5, this protein association exists as a tri-component complex, which contains also PDGF $\beta-R$ molecules. Mutational analyses have demonstrated that glutamic acid 143 in the transmembrane domain of the $16 \mathrm{kDa}$ protein and glutamine 17 in the transmembrane domain of BPV-1 E5 are essential for E5-16 kDa stable association [172]. The binding of the E5 with $16 \mathrm{kDa}$ perturbs the correct assembly of V-ATPase and $\mathrm{H}+$ pumping, with persistent alkalinization of the GA and endosomal vesicles [103] and may lead, directly or indirectly, to a marked loss of cell-cell communication through downregulation of gap junctions (Table 1) [101,173], rendering the transformed cells more insensitive to homeostatic growth control signals from adjacent normal cells. However, in the case of HPV-16 inhibition of gap junction intercellular communication has been attributed to the interaction of E5 with connexin 43 [84]. E5-expressing bovine urinary bladder tumours show activated 


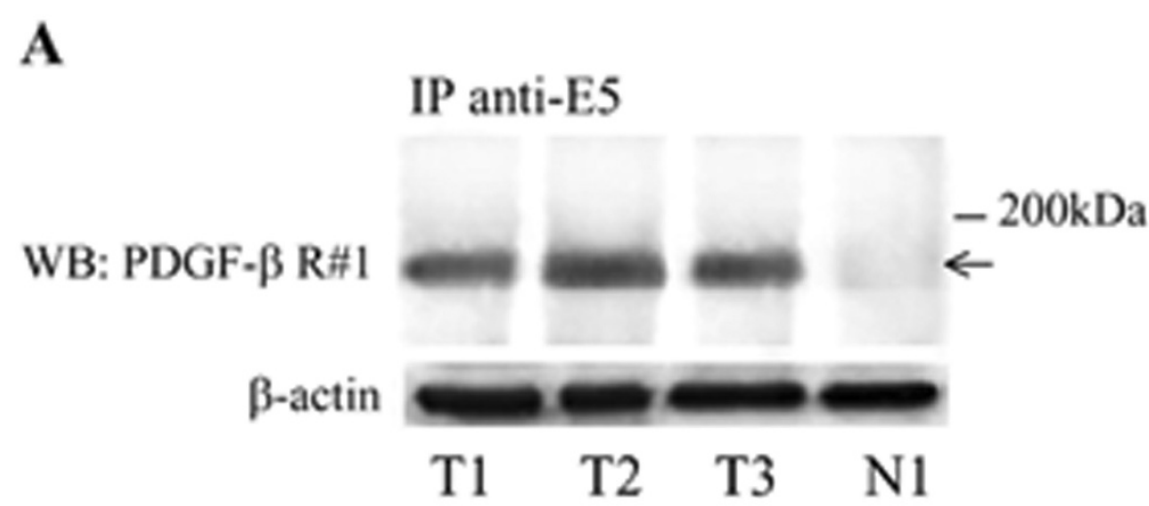

B
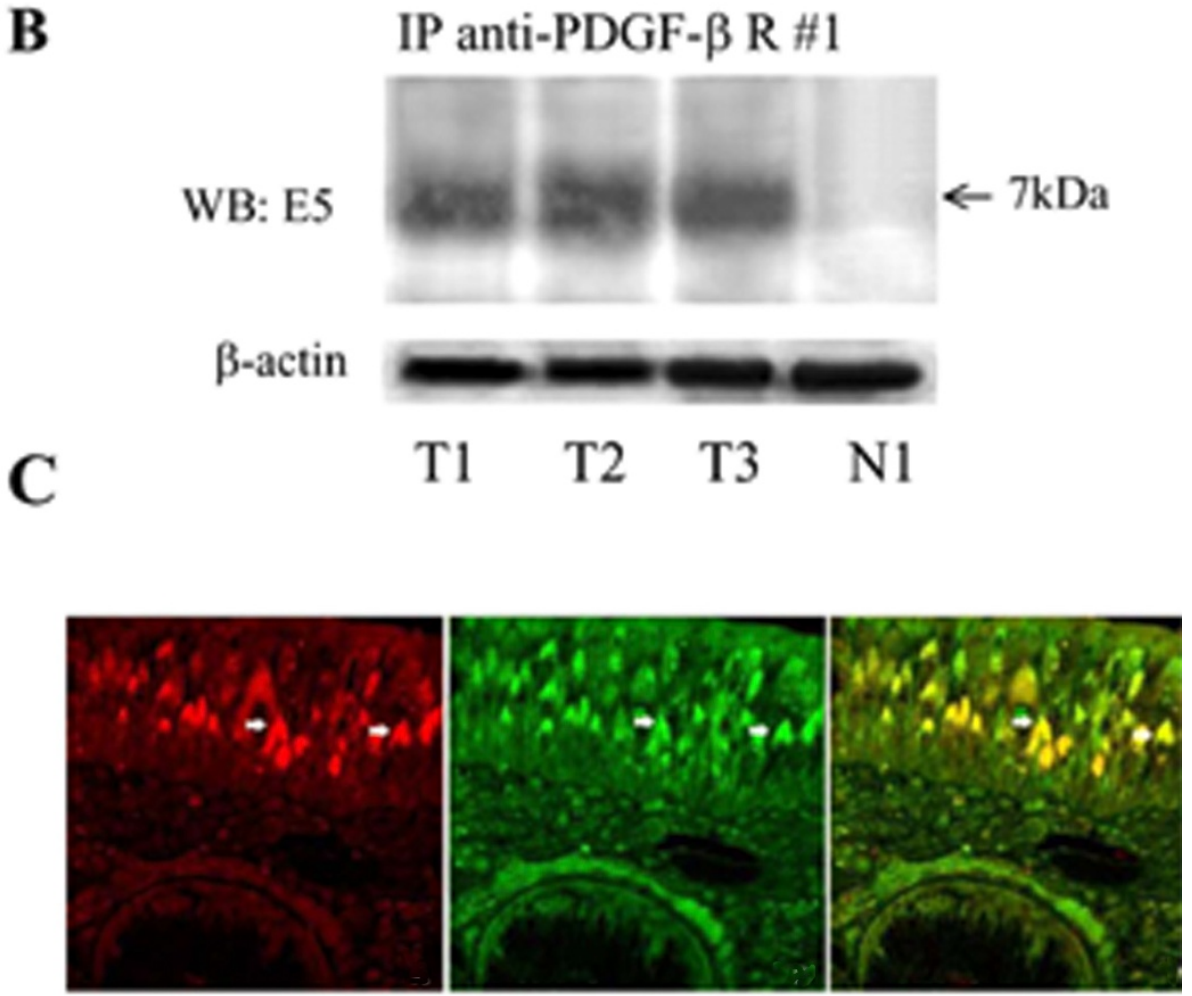

Figure 3 BPV E5 and PDGF $\beta$-receptor co-precipitate and co-localize in bovine urinary bladder carcinoma. A. Co-immunoprecipitation of the PDGF $\beta$-receptor with E5 antiserum. Tissue lysates were immunoprecipitated with the anti E5 antibody and the immunoblot was analyzed with the anti- PDGF $\beta$-receptor antibody. Lanes 1-3 are BPV-2 positive bovine urinary bladder cancer samples, T1, T2, T3. Lane 4 is BPV-2 DNA positive normal bovine bladder mucosa, N1. B. Coimmunoprecipitation of the E5 oncoprotein with the PDGF $\beta$-receptor antiserum. The arrow indicates the $\mathrm{E} 5$ oncoprotein and its estimated $\mathrm{kDa}$ weight. In a parallel blot, the same amount of lysate was probed with an antibody to $\beta$-actin to control for the quantity of protein (bottom panel) C. Colocalization (yellow) of PDGF $\beta$-receptor (red) and E5 (green) in bovine neoplastic urothelium. The white arrows indicate a juxtanuclear position of E5 and PDGF $\beta$-receptor (reproduced with permission from Borzacchiello et al., Oncogene 2006).

calpain 3, suggesting a possible involvement of this protein in urothelial carcinogenesis [174].

\section{Targeting HPV-16 E5 for cervical treatment}

16E5 activates many different cellular pathways involved mostly in the early stage of cervical carcinogenesis
[175]. Different studies have pointed out the possibility of E5 targeting for $\mathrm{CaCx}$ therapy. In animal studies, $16 \mathrm{E} 5$ delivered by an adenovirus vector reduces the growth of tumours and the E5 vaccine induces protection against tumours through $\mathrm{CD}^{+}$cytotoxic $\mathrm{T}$ cells (CTLs) [176]. The same research group has further 


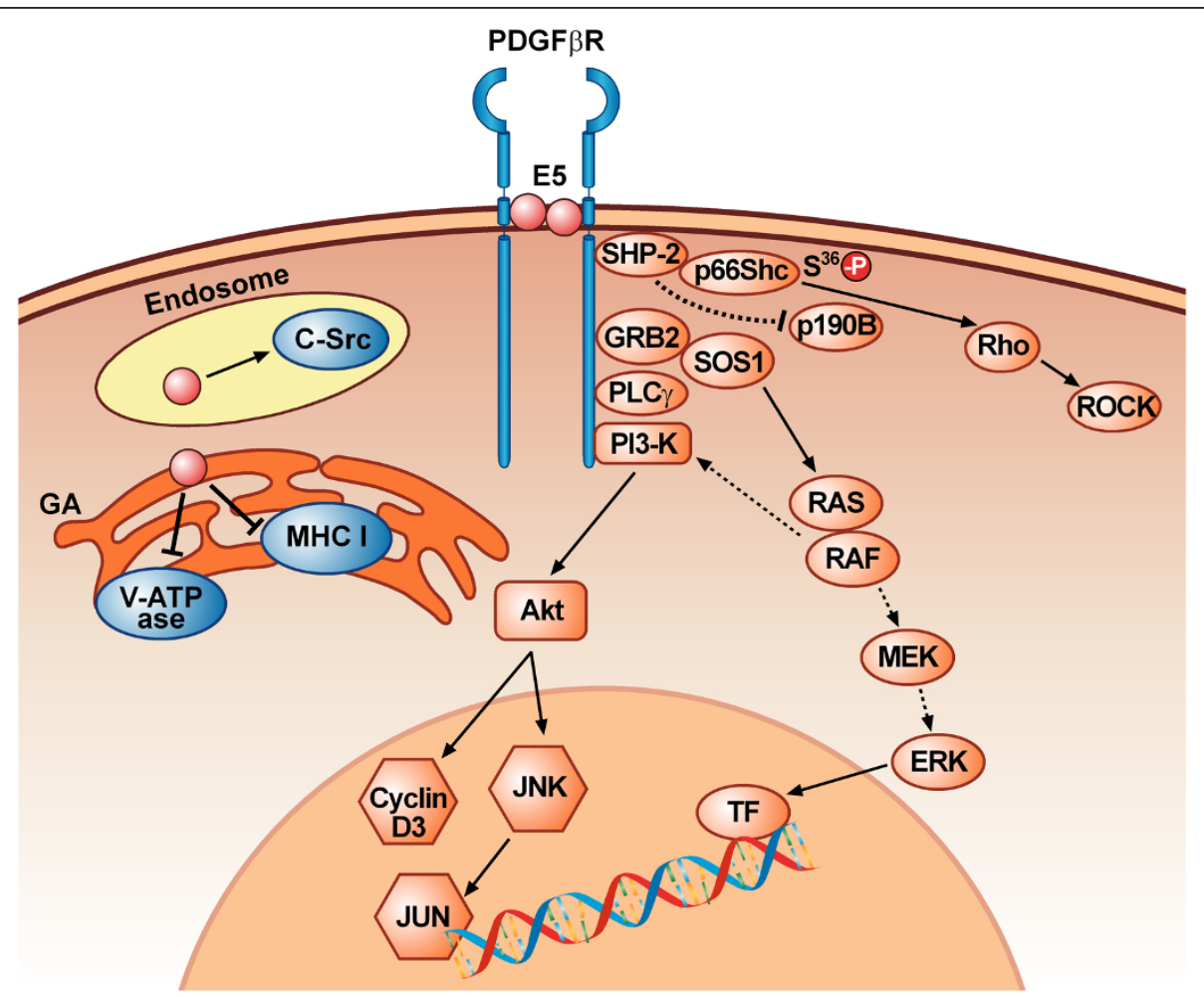

Figure 4 Model of cellular events during cell transformation mediated by BPV-1 E5. E5 binds to the transmembrane domain of PDGF $\beta$-R and induces receptor dimerisation and autophosphorylation. The activated receptor can recruit p85-PI3K that activates the AKT and JNK pathway. PDGF $\beta$ R stimulation of a PI3K-AKTpathway leads to increased expression of cyclin D3. Recruitment of Sos1-GRB2 complex to p-PDGF $3 R$ may activate Ras, although the downstream MAPK pathway is not activated; therefore Ras may activate PI3-K pathway. The SHP2-p66Shc complex bound to the activated PDGF $\beta-R$ may be recruited and inactivates p190BRhoGAP, resulting in activation of a Rho family GTPase, Rho A and its downstream effector ROCK inducing focus formation. E5 is able to interact with c-src in late endosomal and trans-Golgi compartment, thus resulting in C-src constitutively activation. E5 interacts with the C-terminus of MHC I heavy chain and causes the retention of MHC I in the Golgi apparatus, thus preventing its transport to the cell surface. E5 perturbs the physiological activity of the V-ATPase by inhibiting the correct assembly of V-ATPase and $\mathrm{H}+$ pumping, thus inducing persistent alkalinization of the Golgi and endosomes vescicles.

demonstrated that the stimulating epitope was an E5 peptide (aminoacids 25-33) and vaccination with this peptide carrying $\mathrm{CpG}$ oligonucleotides reduced tumour growth [177]. 16E5 modulates different cellular pathways and the targeting of these relevant pathways may lead in a near future to a possible therapeutic approach. In addition, E5 is more consistently expressed in the early stage of viral infection and in precancerous lesions [178], and therefore E5 or E5 altered pathways could be targeted to cure the infection and to prevent precancerous lesions from progressing into invasive cancers. 16E5 interacts with many different pathways including upregulation of growth factor signalling, induction of inflammatory cell signalling, angiogenesis and antiapoptosis (Figure 2). Furthermore E5 participates in malignant transformation by supplementing (added value) the roles of E6 and E7. All these E5-induced signalling pathways (Figure 2) or E5 itself can be addressed by therapies already utilised against the other HPV oncogenes such as radioimmunotherapy, oncolytic adenoviruses [179], gene silencing using short interfering RNA (siRNA) [180] and others, which have been originally used to target the E5-upregulated pathways. EGF-R, COX-2 or ET1 inhibitors should be useful in controlling E5 activity in the precancerous lesions as well as other small molecules interfering with downstream molecules. Finally, E5 may be considered a viroporin, like the VP4 of SV40 [181] and, therefore, susceptible of therapy by compounds that affect similar structures produced by other viruses. Indeed amantidine, amiloride, long-alkyl-chain iminosugar derivatives and new compounds seem to affect, to various extent, the activity of the 16E5 protein in vitro (A. Macdonald, personal communication, 11 DNA TV Meeting, Trieste, Italy, 2011)

\section{Conclusions}

The main activities of E5 can be resumed as follows:

Although E6 and E7 provide the primary transforming activities of HR HPVs, E5 can augment their function and contribute to tumour progression: 
When expressed alone, HPV E5 has weak transforming activity.

In transgenic mouse models, 16E5 expression in the skin produces epithelial hyperproliferation with spontaneous tumour formation, whereas in estrogen-treated mice, expression of E5 alone can induce cancers [182], suggesting a role for $\mathrm{E} 5$ as a true oncoprotein.

The presence in HPV 16-positive cervical tumours of viral episomes in addition to viral integrants leads to the hypothesis that there are multiple pathways to HPV induced tumourigenesis see above. Beside the basic hypothesis of high-level expression of E6 and E7 consequent to the abrogation of the repressive effects of E2 due to the loss of the E2 gene during integration, another pathway can be active in cells that still maintain viral episomes, in which E5 would augment the activity of E6 and E7. The expression of E5 is increased on differentiation to promote proliferation of differentiated cells and productive viral replication.

The localization of HPV E5 to the endoplasmic reticulum suggests its activity may be related to the trafficking of cytoplasmic membrane proteins through this cellular compartment, in particular of growth factor receptors and of molecules involved in immune control.

There are multiple documented intracellular binding targets for 16E5 such as the EGF receptor family member ErbB4 [77], the $16-\mathrm{kDa}$ subunit of the vacuolar $\mathrm{H}$ ${ }^{+}$-ATPase [39,55], the heavy chain of HLA type I [104], calnexin [51], the zinc transporter ZnT-1, the EVER1 and EVER2 transmembrane channel-like proteins $[115,117]$ the nuclear import receptor family member KNß3 [45], BAP31 and A4 [44,52] (Figure 2).

However the role of 16E5 in carcinogenesis seems to be limited to the early stages of cervical carcinogenesis because the E5 gene is frequently deleted when the HPV genome is integrated during malignant progression $[28,68,183]$. Nevertheless, the expression of $16 \mathrm{E} 5$ as detected by immunohistochemistry, was reported in approximately 80,90 and $60 \%$ of HPV 16-infected LSILs, high-grade SILs and cervical carcinomas, respectively [28]. Furthermore data from a limited number of patients were presented at the $1^{\text {st }}$ International Workshop on E5 Oncogene [184] suggesting that E5 expression may lead to a worse response to treatment with taxanes (Venuti, unpublished data). Therefore, targeting E5 which is frequently expressed in earlier stages of malignant transformation may be a rational approach for preventing premalignant lesions from progressing into invasive cervical cancers [175]. The recent successful eradication of HPV-induced tumours in mice by anti-E5 vaccination [176] indicates that E5 can be used in immunotherapy. The neutralization of E5 or of E5induced signalling pathways, therefore, whether immunological or chemical, could be advantageous particularly in HPV infections and pre-cancerous lesions where there are no treatments available.

\section{List of abbreviations used}

HR: High Risk; PV: Papillomavirus; 16E5: HPV-16 E5; CxCa: cancer of the uterine cervix; PAP test: Papanicolau test; E: early proteins; L: late structural proteins; ORF: open reading frame; LSIL: low grade squamous intraepithelial lesions; CIN: cervical intraepithelial neoplasia; GA: Golgi apparatus; ER: endoplasmic reticulum; KNß3: karyopherin $\beta 3$; MHC I: Major histocompatibility complex class I; MHC II: Major histocompatibility complex class II; HLA: human leukocyte antigen; CTL: cytotoxic T Lymphocyte; EGF-R: epidermal growth factor receptor; NK: natural killer; MAPK: mitogen-activated protein kinase; PKC: protein kinase $C_{;} E_{A}$ : endothelin receptor; ET-1: endothelin-1; CKI: cyclin-dependent protein kinase inhibitors; TRAIL: Tumor necrosis factor-related apoptosis-inducing ligand; DISC: Death-Inducing Signalling Complex; FasL: Tumor necrosis factor ligand superfamily member; COX-2: cyclooxygenase 2; $\mathrm{PGE}_{2}$ : Prostaglandin E2 receptor; XBP-1: X-boxbinding protein 1; IRE: Serine/threonine-protein kinase/endoribonuclease IRE1; IFN: interferon; CREB: Cyclic AMP-responsive element-binding protein; PDGF $\beta$-R: Platelet Derived Growth Factor Receptor $\beta$ subunit receptor; PI3K: phosphoinositide3 kinase; V-ATPase: vacuolar H+-ATPase.

\section{Acknowledgements}

MSC thanks Cancer Research UK for its continuous support throughout her career. This work was supported by grant PRIN - Ministero dell'Istruzione, Università e Ricerca Scientifica (MIUR) protocol number 2008LTY389. AV and FP thanks Lega Italiana Lotta Tumori (LILT) for supporting their researches.

\section{Author details}

${ }^{1}$ Laboratory of Virology, Regina Elena Cancer Institute, Rome, Italy. ${ }^{2}$ Institute of Infection Immunity and Inflammation, University of Glasgow, Scotland, UK. ${ }^{3}$ Department of Pathology and Animal health, University of Naples Federico II, Naples, Italy. ${ }^{4}$ University of Glasgow, Glasgow, Scotland, UK.

\section{Authors' contributions}

All authors have contributed equally to the paper. All authors read and approved the final manuscript.

\section{Competing interests}

The authors declare that they have no competing interests.

Received: 28 July 2011 Accepted: 11 November 2011 Published: 11 November 2011

\section{References}

1. IARC Working Group: Human papillomaviruses. Lyon, International Agency for research on cancer; 199564.

2. Walboomers JM, Jacobs MV, Manos MM, Bosch FX, Kummer JA, Shah KV, Snijders PJ, Peto J, Meijer CJ, Muñoz N: Human papillomavirus is a necessary cause of invasive cervical cancer worldwide. J Pathol 1999, 189:12-19.

3. Frazer $\mathrm{H}$ : Prevention of cervical cancer through papillomavirus vaccination. Nat Rev Immunol 2004, 4:46-54

4. Parkin DM, Bray F: Chapter 2: The burden of HPV-related cancers. Vaccine 2006, 24:11-25.

5. Syrjänen S, Lodi G, von Bültzingslöwen I, Aliko A, Arduino P, Campisi G, Challacombe S, Ficarra G, Flaitz C, Zhou HM, Maeda H, Miller C, Jontell M: Human papillomaviruses in oral carcinoma and oral potentially malignant disorders: a systematic review. Oral Dis 2011, 17:58-72.

6. Klozar J, Tachezy R, Rotnáglová E, Koslabová E, Saláková M, Hamsíková E: Human papillomavirus in head and neck tumors: epidemiological, molecular and clinical aspects. Wien Med Wochenschr 2010, 160:305-309.

7. Zafer E, Ergun MA, Alver G, Sahin Fl, Yavuzer S, Ekmekci A: Detection and typing of human papillomavirus in non-small cell lung cancer. Respiration 2004, 71:88-90.

8. Gillison ML: Human papillomavirus-associated head and neck cancer is a distinct epidemiologic, clinical, and molecular entity. Semin Oncol 2004, 31:744-754.

9. Syrjänen KJ: HPV infections in benign and malignant sinonasal lesions. $J$ Clin Pathol 2003, 56:174-181. 
10. zur Hausen $\mathrm{H}$ : Yohei Ito Memorial Lecture: Papillomaviruses in human cancers. Leukemia 1999, 13:1-5.

11. Audeau A, Han HW, Johnston MJ, Whitehead MW, Frizelle FA: Does human papilloma virus have a role in squamous cell carcinoma of the colon and upper rectum? Eur J Surg Oncol 2002, 28:657-660.

12. Damin AP, Karam R, Zettler CG, Caleffi M, Alexandre CO: Evidence for an association of human papillomavirus and breast carcinomas. Breast Cancer Res Treat 2004, 84:131-137.

13. Shigehara K, Sasagawa T, Kawaguchi S, Nakashima T, Shimamura M, Maeda Y, Konaka H, Mizokami A, Koh E, Namiki M: Etiologic role of human papillomavirus infection in bladder carcinoma. Cancer 2011, 117:2067-2076

14. Martinez-Fierro ML, Leach RJ, Gomez-Guerra LS, Garza-Guajardo R, JohnsonPais T, Beuten J, Morales-Rodriguez IB, Hernandez-Ordoñez MA, CalderonCardenas G, Ortiz-Lopez R, Rivas-Estilla AM, Ancer-Rodriguez J, RojasMartinez A: Identification of viral infections in the prostate and evaluation of their association with cancer. BMC Cancer 2010, 10:326.

15. Borzacchiello G, Roperto F, Nasir L, Campo MS: Human papillomavirus research: do we still need animal models? Int J Cancer 2009, 125:739-740.

16. Werness BA, Levine AJ, Howley PM: Association of human papillomavirus types 16 and 18 E6 proteins with p53. Science 1990, 248:76-79.

17. Scheffner M, Werness BA, Huibregtse JM, Levine AJ, Howley PM: The E6 oncoprotein encoded by human papillomavirus types 16 and 18 promotes the degradation of p53. Cell 1990, 63:1129-1136.

18. Moody CA, Laimins LA: Human papillomavirus oncoproteins: pathways to transformation. Nat Rev Cancer 2010, 10:550-560.

19. Bernard HU, Burk RD, Chen Z, van Doorslaer $K$, Hausen $H$, de Villiers EM: Classification of papillomaviruses (PVs) based on 189 PV types and proposal of taxonomic amendments. Virology 2010, 401:70-79.

20. Muñoz N, Bosch FX, de Sanjosé S, Herrero R, Castellsagué X, Shah KV, Snijders PJ, Meijer CJ, International Agency for Research on Cancer Multicenter Cervical Cancer Study Group: Epidemiologic classification of human papillomavirus types associated with cervical cancer. N Engl J Med 2003, 348:518-527.

21. Nath R, Mant CA, Kell B, Cason J, Bible JM: Analyses of variant human papillomavirus type-16 E5 proteins for their ability to induce mitogenesis of murine fibroblasts. Cancer Cell Int 2006, 6:19-27.

22. Bravo IG, Alonso A: Mucosal human papillomaviruses encode four different E5 proteins whose chemistry and phylogeny correlate with malignant or benign growth. J Virol 2004, 78:13613-13626.

23. Schiffman M, Herrero R, Desalle R, Hildesheim A, Wacholder S, Rodriguez AC, Bratti MC, Sherman ME, Morales J, Guillen D, Alfaro M, Hutchinson M, Wright TC, Solomon D, Chen Z, Schussler J, Castle PE, Burk RD: The carcinogenicity of human papillomavirus types reflects viral evolution. Virology 2005, 337:76-84.

24. Garcia-Vallve S, Alonso A, Bravo IG: Papillomaviruses: different genes have different histories. Trends Microbiol 2005, 13:514-521.

25. Longworth MS, Laimins LA: Pathogenesis of human papillomaviruses in differentiating epithelia. Microbiol Mol Biol Rev 2004, 68:362-372.

26. Burnett S, Jareborg N, DiMaio D: Localization of bovine papillomavirus type 1 E5 protein to transformed basal keratinocytes and permissive differentiated cells in fibropapilloma tissue. Proc Natl Acad Sci USA 1992, 89:5665-5669.

27. Araibi EH, Marchetti $B$, Ashrafi GH, Campo MS: Downregulation of major histocompatibility complex class I in bovine papillomas. J Gen Virol 2004, 85:2809-2814.

28. Chang JL, Tsao YP, Liu DW, Huang SJ, Lee WH, Chen SL: The expression of HPV- 16 E5 protein in squamous neoplastic changes in the uterine cervix. J Biomed Sci 2001, 8:206-213.

29. Chen SL, Mounts P: Transforming activity of E5a protein of human papillomavirus type 6 in NIH 3T3 and C127 cells. J Virol 1990, 64:3226-3233.

30. Leechanachai $P$, Banks L, Moreau F, Matlashewski G: The E5 gene from human papillomavirus type 16 is an oncogene which enhances growth factor-mediated signal transduction to the nucleus. Oncogene 1992, 7:19-25.

31. Leptak C, Ramon y Cajal S, Kulke R, Horwitz BH, Riese DJ, Dotto GP, DiMaio D: Tumorigenic transformation of murine keratinocytes by the E5 genes of bovine papillomavirus type 1 and human papillomavirus type 16. J Virol 1991, 65:7078-7083.
32. Pim D, Collins M, Banks L: Human papillomavirus type 16 E5 gene stimulates the transforming activity of the epidermal growth factor receptor. Oncogene 1992, 7:27-32

33. Bouvard V, Matlashewski G, Gu ZM, Storey A, Banks L: The human papillomavirus type 16 E5 gene cooperates with the E7 gene to stimulate proliferation of primary cells and increases viral gene expression. Virology 1994, 203:73-80.

34. Straight SW, Herman B, McCance DJ: The E5 oncoprotein of human papillomavirus type 16 inhibits the acidification of endosomes in human keratinocytes. J Virol 1995, 69:3185-3192.

35. Valle FG, Banks L: The human papillomavirus (HPV)-6 and HPV-16 E5 proteins co-operate with HPV-16 E7 in the transformation of primary rodent cells. J Gen Virol 1995, 76:1239-1245.

36. Venuti A, Salani D, Poggiali F, Manni V, Bagnato A: The E5 oncoprotein of human papillomavirus type 16 enhances endothelin-1-induced keratinocyte growth. Virology 1998, 248:1-5.

37. Ghai J, Ostrow RS, Tolar J, McGlennen RC, Lemke TD, Tobolt D, Liu Z, Faras AJ: The E5 gene product of rhesus papillomavirus is an activator of endogenous Ras and phosphatidylinositol-3'-kinase in NIH 3T3 cells. Proc Natl Acad Sci USA 1996, 93:12879-12884.

38. Rho J, de Villiers EM, Choe J: Transforming activities of human papillomavirus type 59 E5, E6 and E7 open reading frames in mouse C127 cells. Virus Res 1996, 44:57-65.

39. Conrad M, Bubb VJ, Schlegel R: The human papillomavirus type 6 and 16 E5 proteins are membrane-associated proteins which associate with the 16-kilodalton pore-forming protein. J Virol 1993, 67:6170-6178.

40. Disbrow GL, Sunitha I, Baker CC, Hanover J, Schlegel R: Codon optimization of the HPV-16 E5 gene enhances protein expression. Virology 2003, 311:105-114.

41. Hu L, Ceresa BP: Characterization of the plasma membrane localization and orientation of HPV16 E5 for cell-cell fusion. Virology 2009, 393:135-143.

42. Hu L, Plafker K, Vorozhko V: Human papillomavirus E5 induces binucleated cell formation by cell-cell fusion. Virology 2009, 384:125-134

43. Hu L, Potapova TA, Li S: Expression of HPV16 E5 produces enlarged nuclei and polyploidy through endoreplication. Virology 2010, 405:342-351.

44. Krawczyk E, Suprynowicz FA, Sudarshan SR, Schlegel R: Membrane orientation of the human papillomavirus type 16 E5 oncoprotein. J Virol 2010, 84:1696-1703.

45. Hanover JA, Schlegel R, Suprynowicz FA: Karyopherin $\beta 3$ : a new cellular target for the HPV-16 E5 oncoprotein. Biochem Biophys Res Commun 2008, 371:684-688.

46. Deane R, Schäfer W, Zimmermann HP, Mueller L, Goörlich D, Prehn S, Ponstingl H, Bischoff FR: Ran-binding protein 5 (RanBP5) is related to the nuclear transport factor importin-beta but interacts differently with RanBP1. Mol Cell Biol 1997, 17:5087-5096.

47. Yaseen NR, Blobel G: Cloning and characterization of human karyopherin 33. Proc Natl Acad Sci USA 1997, 94:4451-4456.

48. Burkhardt A, Willingham M, Gay C, Jeang KT, Schlegel R: The E5 oncoprotein of bovine papillomavirus is oriented asymmetrically in Golgi and plasma membranes. Virology 1989, 170:334-339.

49. Yang DH, Wildeman AG, Sharom FJ: Overexpression, purification, and structural analysis of the hydrophobic E5 protein from human papillomavirus type 16. Protein Expr Purif 2003, 30:1-10.

50. Gieswein CE, Sharom FJ, Wildeman AG: Oligomerization of the E5 protein of human papillomavirus type 16 occurs through multiple hydrophobic regions. Virology 2003, 313:415-426.

51. Gruener M, Bravo IG, Momburg F, Alonso A, Tomakidi P: The E5 protein of the human papillomavirus type 16 down-regulates HLA-I surface expression in calnexin expressing but not in calnexin-deficient cells. Virol J 2007, 4:116-130.

52. Regan JA, Laimins LA: Bap31 is a novel target of the human papillomavirus E5 protein. J Virol 2008, 82:10042-10051.

53. Cortese MS, Ashrafi GH, Campo MS: All four di-leucine motifs in the first hydrophobic domain of the E5 oncoprotein of human papillomavirus type 16 are essential for surface MHC class I downregulation activity and E5 endomembrane localization. Int J Cancer 2010, 126:1675-1682.

54. Adam $J$, Briggs MW, McCance DJ: A mutagenic analysis of the E5 protein of human papillomavirus type 16 reveals that E5 binding to the 
vacuolar H+-ATPase is not sufficient for biological activity, using mammalian and yeast expression systems. Virology 2000, 272:315-325.

55. Rodriguez Ml, Finbow ME, Alonso A: Binding of human papillomavirus 16 E5 to the $16 \mathrm{kDa}$ subunit c (proteolipid) of the vacuolar H+-ATPase can be dissociated from the E5-mediated epidermal growth factor receptor overactivation. Oncogene 2000, 19:3727-3732.

56. Krawczyk E, Suprynowicz FA, Liu X, Dai Y, Hartmann DP, Hanover J, Schlegel R: Koilocytosis: a cooperative interaction between the human papillomavirus E5 and E6 oncoproteins. Am J Pathol 2008, 173:682-688.

57. Krawczyk E, Suprynowicz FA, Hebert JD, Kamonjoh CM, Schlegel R: The human papillomavirus type 16 E5 oncoprotein translocates calpactin I to the perinuclear region. J Virol 2011, 85:10968-10975.

58. Straight SW, Hinkle PM, Jewers RJ, McCance DJ: The E5 oncoprotein of human papillomavirus type 16 transforms fibroblasts and effects the downregulation of the epidermal growth factor receptor in keratinocytes. J Virol 1993, 67:4521-4532.

59. Mittal KR, Chan W, Demopoulos RL: Sensitivity and specificity of various morphological features of cervical condylomas. Arch Pathol Lab Med 1990, 114:1038-1041.

60. Prasad CJ, Sheets E, Selig AM, McArthur MC, Crum CP: The bi-nucleated squamous cell: histologic spectrum and relationship to low-grade squamous intraepithelial lesions. Mod Pathol 1993, 6:313-317.

61. Wright TC, Gatscha RM, Luff RD, Prey MU: Epithelial cell abnormalities: squamous. In The Bethesda System for Reporting Cervical Cytology.. 2 edition. Edited by: Solomon D, Nayar R. New York: Springer-Verlag; 2004:89-123.

62. Olaharski AJ, Sotelo R, Solorza-Luna G, Gonsebatt ME, Guzman P, Mohar A, Eastmond DA: Tetraploidy and chromosomal instability are early events during cervical carcinogenesis. Carcinogenesis 2006, 27:337-343.

63. Egawa K: Do human papillomaviruses target epidermal stem cells? Dermatology 2003, 207:251-254

64. McMurray HR, Nguyen D, Westbrook TF, McAnce DJ: Biology of human papillomaviruses. Int J Exp Pathol 2001, 82:15-33.

65. zur Hausen H: Papillomaviruses and cancer: from basic studies to clinical application. Nat Rev Cancer 2002, 2:342-350.

66. Fehrmann F, Laimins LA: Human papillomaviruses: targeting differentiating epithelial cells for malignant transformation. Oncogene 2003, 22:5201-5207.

67. Genther Williams SM, Disbrow GL, Schlegel R, Lee D, Threadgill DW, Lambert PF: Requirement of epidermal growth factor receptor for hyperplasia induced by E5, a high-risk human papillomavirus oncogene. Cancer Research 2005, 65:6534-6542.

68. DiMaio D, Mattoon D: Mechanism s of cell transformation by papillomavirus E5 proteins. Oncogene 2001, 20:7866-7873.

69. Thomsen P, van Deurs B, Norrild B, Kayser L: The HPV16 E5 oncogene inhibits endocytic trafficking. Oncogene 2000, 19:6023-6032.

70. Crusius K, Rodriguez I, Alonso A: The human papillomavirus type 16 E5 protein modulates ERK1/2 and p38 MAP kinase activation by an EGFRindependent process in stressed human keratinocytes. Virus Genes 2000, 20:65-69.

71. Crusius K, Auvinen E, Alonso A: Enhancement of EGF- and PMA-mediated MAP kinase activation in cells expressing the human papillomavirus type 16 E5 protein. Oncogene 1997, 15:1437-1444.

72. Gu Z, Matlashewski G: Effect of human papillomavirus type 16 oncogenes on MAP kinase activity. J Virol 1995, 69:8051-8056

73. Chen SL, Huang CH, Tsai TC, Lu KY, Tsao YP: The regulation mechanism of c-jun and junB by human papillomavirus type 16 E5 oncoprotein. Arch Virol 1996, 141:791-800

74. Chen SL, Lin YK, Li LY, Tsao YP, Lo HY, Wang WB, Tsai TC: E5 proteins of human papillomavirus types 11 and 16 transactivate the c-fos promoter through the NF1 binding element. J Virol 1996, 70:8558-8563.

75. Crusius K, Auvinen E, Steuer B, Gaissert H, Alonso A: The human papillomavirus type 16 E5-protein modulates ligand-dependent activation of the EGF receptor family in the human epithelial cell line HaCaT. Exp Cell Res 1998, 241:76-83.

76. Hwang ES, Nottoli T, Dimaio D: The HPV16 E5 protein: expression, detection, and stable complex formation with transmembrane proteins in COS cells. Virology 1995, 211:227-233.

77. Chen SL, Lin ST, Tsai TC, Hsiao WC, Tsao YP: ErbB4 (JM-b/CYT-1)-induced expression and phosphorylation of c-Jun is abrogated by human papillomavirus type 16 E5 protein. Oncogene 2007, 26:42-53.
78. Simeone P, Teson M, Latini A, Carducci M, Venuti A: Endothelin-1 could be one of the targets of psoriasis therapy. Br J Dermatol 2004, 151:1273-1275.

79. Bagnato A, Loizidou M, Pflug BR, Curwen J, Growcott J: Role of the endothelin axis and its antagonists in the treatment of cancer. $\mathrm{Br} J$ Pharmacol 2011, 163:220-233.

80. Belleudi F, Leone L, Purpura V, Cannella F, Scrofani C, Torrisi MR: HPV16 E5 affects the KGFR/FGFR2b-mediated epithelial growth through alteration of the receptor expression, signalling and endocytic traffic. Oncogene 2011.

81. Tsao YP, Li LY, Tsai TC, Chen SL: Human papillomavirus type 11 and 16 E5 represses p21(Wafl/Sdil/Cipl) gene expression in fibroblasts and keratinocytes. J Virol 1996, 70:7535-7539.

82. Pedroza-Saavedra A, Lam EW, Esquivel-Guadarrama F, GutierrezXicotencatl L: The human papillomavirus type 16 E5 oncoprotein synergizes with EGFreceptor signalling to enhance cell cycle progression and the down-regulation of p27(Kip1). Virology 2010, 400:44-52.

83. Oelze I, Kartenbeck J, Crusius K, Alonso A: Human papillomavirus type 16 E5 protein affects cell-cell communication in an epithelial cell line. J Virol 1995, 69:4489-4494.

84. Tomakidi P, Cheng H, Kohl A, Komposch G, Alonso A: Connexin 43 expression is downregulated in raft cultures of human keratinocytes expressing the human papillomavirus type 16 E5 protein. Cell Tissue Res 2000, 301:323-327.

85. Stoler MH, Rhodes CR, Whitbeck A, Wolinsky SM, Chow LT, Broker TR: Human papillomavirus type 16 and 18 gene expression in cervical neoplasias. Hum Pathol 1992, 23:117-128.

86. Kell B, Jewers RJ, Cason J, Pakarian F, Kaye JN, Best JM: Detection of E5 oncoprotein in human papillomavirus type 16-positive cervical scrapes using antibodies raised to synthetic peptides. J Gen Virol 1994, 75:2451-2456.

87. Kabsch $\mathrm{K}$, Alonso A: The human papillomavirus type $16 \mathrm{E} 5$ protein impairs TRAIL- and FasL-mediated apoptosis in $\mathrm{HaCaT}$ cells by different mechanisms. J Virol 2002, 76:12162-12172.

88. Kabsch K, Mossadegh N, . Kohl A, Komposch G, Schenkel J, Alonso A, Tomakidi P: The HPV-16 E5 protein inhibits TRAIL- and FasL-mediated apoptosis in human keratinocyte raft cultures. Intervirology 2004, 47:48-56.

89. Zhang B, Spandau DF, Roman A: E5 protein of human papillomavirus type 16 protects human foreskin keratinocytes from UV B-irradiationinduced apoptosis. J Virol 2002, 76:220-231.

90. Kabsch K, Alonso A: The human papillomavirus type 16 (HPV-16) E5 protein sensitizes human keratinocytes to apoptosis induced by osmotic stress. Oncogene 2002, 21:947-953.

91. Tardif KD, Mori K, Kaufman RJ, Siddiqui A: Hepatitis C virus suppresses the IRE1-XBP1 pathway of the unfolded protein response. J Biol Chem 2004, 279:17158-17164.

92. Schiffman M, Castle PE: The promise of global cervical-cancer prevention. N Engl J Med 2005, 353:2101-2104.

93. Condjella R, Liu X, Suprynowicz F, Yuan H, Sudarshan S, Dai Y, Schlegel R: The canine papillomavirus E5 protein signals from the endoplasmic reticulum. J Virol 2009, 83:12833-12841.

94. Wu R, Abramson AL, Shikowitz MJ, Dannenberg AJ, Steinberg BM: Epidermal growth factor-induced cyclooxygenase-2 expression is mediated through phosphatidylinositol-3 kinase, not mitogen-activated protein/extracellular signal-regulated kinase kinase, in recurrent respiratory papillomas. Clin Cancer Res 2005, 11:6155-6161.

95. Wu R, Coniglio SJ, Chan A, Symons MH, Steinberg BM: Up-regulation of Rac1 by epidermal growth factor mediates COX-2 expression in recurrent respiratory papillomas. Mol Med 2007, 13:143-150.

96. Subbaramaiah K, Dannenberg AJ: Cyclooxygenase-2 transcription is regulated by human papillomavirus $16 \mathrm{E} 6$ and E7 oncoproteins: evidence of a corepressor/coactivator exchange. Cancer Res 2007, 67:3976-3985.

97. Kim SH, Oh JM, No JH, Bang YJ, Juhnn YS, Song YS: Involvement of NFkappaB and AP-1 in COX-2 upregulation by human papillomavirus 16 E5 oncoprotein. Carcinogenesis 2009, 30:753-757.

98. Sudarshan SR, Schlegel R, Liu X: The HPV-16 E5 protein represses expression of stress pathway genes XBP-1 and COX-2 in genital keratinocytes. Biochem Biophys Res Commun 2010, 399:617-622.

99. Oh JM, Lee YI, Song YS, Kim WH, Juhnn YS: Human papillomavirus E5 protein induces expression of the EP4 subtype of prostaglandin E2 
receptor in cyclic AMP response element-dependent pathways in cervical cancer cells. Carcinogenesis 2009, 30:141-149.

100. Stanley MA, Pett MR, Coleman N: HPV: from infection to cancer. Biochem Soc Trans 2007, 35:1456-1460

101. O'Brien PM, Campo MS: Evasion of host immunity directed by papillomavirus encoded proteins. Virus Res 2002, 1:103-118.

102. Ashrafi GH, Haghshenas MR, Marchetti B, O'Brien PM, Campo MS: The E5 protein of human papillomavirus type 16 selectively down-regulates surface HLA class. Int J Cancer 2005, 113:276-283.

103. Schapiro F, Sparkowski J, Adduci A, Schlegel R, Grinstein S: Golgi alkalinization by the papillomavirus E5 oncoprotein. J Cell Biol 2000, 148:305-315.

104. Ashrafi GH, Haghshenas M, Marchetti B, Campo MS: E5 protein of human papillomavirus 16 downregulates HLA class I and interacts with the heavy chain via its first hydrophobic domain. Int J Cancer 2006, 119:2105-2112.

105. Araibi EH, Marchetti B, Dornan ES, Ashrafi GH, Dobromylskyj M, Ellis SA, Campo MS: The E5 oncoprotein of BPV-4 does not interfere with the biosynthetic pathway of non-classical MHC class I. Virology 2006, 353:174-183

106. Campo MS, Graham SV, Cortese MS, Ashrafi GH, Araibi EH, Dornan ES, Miners K, Nunes C, Man S: HPV-16 E5 down-regulates expression of surface HLA class I and reduces recognition by CD8 T cells. Virology 2010, 407:137-142.

107. Zhang B, Li P, Wang E, Brahmi Z, Dunn KW, Blum JS, Roman A: The E5 protein of human papillomavirus type 16 perturbs MHC class II antigen maturation in human foreskin keratinocytes treated with interferon- $\gamma$. Virology 2003, 310:100-108.

108. Barnard P, Payne E, McMillan N: The human papillomavirus E7 protein is able to inhibit the antiviral and anti-growth functions of interferon a. Virology 2000, 277:411-419.

109. Lee SJ, Cho YS, Cho MC, Shim JH, Lee KA, Ko KK, Choe YK, Park SN, Hoshino T, Kim S, Dinarello CA, Yoon DY: Both E6 and E7 oncoproteins of human papillomavirus 16 inhibit IL-18-induced IFN-gamma production in human peripheral blood mononuclear and NK cells. J Immunol 2001, 167:497-504.

110. Ronco LV, Karpova AY, Vidal M, Howley PM: Human papillomavirus 16 E6 oncoprotein binds to interferon regulatory factor-3 and inhibits its transcriptional activity. Genes Dev 1998, 12:2061-2072.

111. Miura S, Kawana K, Schust DJ, Fujii T, Yokoyama T, Iwasawa Y, Nagamatsu T, Adachi K, Tomio A, Tomio K, Kojima S, Yasugi T, Kozuma S, Taketani Y: $\mathrm{CD} 1 \mathrm{~d}$, a sentinel molecule bridging innate and adaptive immunity, is downregulated by the human papillomavirus (HPV) E5 protein: a possible mechanism for immune evasion by HPV. J Virol 2010, 84:11614-11623.

112. Obalek S, Favre M, Szymanczyk J, Misiewicz J, Jablonska S, Orth G: Human papillomavirus (HPV) types specific of epidermodysplasia verruciformis detected in warts induced by HPV3 or HPV3-related types in immunosuppressed patients. J Investig Dermatol 1992, 98:936-941.

113. Orth G: Genetics of epidermodysplasia verruciformis: insights into host defense against papillomaviruses. Semin Immunol 2006, 18:362-374.

114. Ramoz N, Rueda LA, Bouadjar B, Montoya LS, Orth G, Favre M: Mutations in two adjacent novel genes are associated with epidermodysplasia verruciformis. Nat Genet 2002, 32:579-581.

115. Lazarczyk M, Pons C, Mendoza JA, Cassonnet P, Jacob Y, Favre M: Regulation of cellular zinc balance as a potential mechanism of EVERmediated protection against pathogenesis by cutaneous oncogenic human papillomaviruses. J Exp Med 2008, 205:35-42.

116. Palmiter RD, Findley SD: Cloning and functional characterization of a mammalian zinc transporter that confers resistance to zinc. EMBO J 1995, 14:639-649.

117. Orth G: Host defenses against human papillomaviruses: lessons from epidermodysplasia verruciformis. Curr Top Microbiol Immunol 2008, 321:59-83

118. Cordano P, Gillan V, Bratlie S, Bouvard V, Banks L, Tommasino M, Campo MS: The E6 E7 oncoproteins of cutaneous human papillomavirus type 38 interfere with the interferon pathway. Virology 2008, 377:408-418.

119. Bible JM, Mant C, Best JM, Kell B, Starkey WG, Shanti Raju K, Seed P, Biswas C, Muir P, Banatvala JE, Cason J: Cervical lesions are associated with human papillomavirus type 16 intratypic variants that have high transcriptional activity and increased usage of common mammalian codons. J Gen Virol 2000, 81:1517-1527.

120. Riley RR, Duensing S, Brake T, Münger K, Lambert PF, Arbeit JM: Dissection of human papillomavirus E6 and E7 function in transgenic mouse models of cervical carcinogenesis. Cancer Res 2003, 63:4862-4871.

121. Genther SM, Sterling S, Duensing S, Münger K, Sattler C, Lambert PF: Quantitative role of the human papillomavirus type 16 E5 gene during the productive stage of the viral life cycle. J Virol 2003, 77:2832-2842.

122. Pett MR, Herdman MT, Palmer RD, Yeo GS, Shivji MK, Stanley MA, Coleman N: Selection of cervical keratinocytes containing integrated HPV16 associates with episome loss and an endogenous antiviral response. Proc Natl Acad Sci USA 2006, 103:3822-3827.

123. Muto V, Stellacci E, Lamberti AG, Perrotti E, Carrabba A, Matera G, Sgarbanti M, Battistini A, Liberto MC, Focà A: Human papillomavirus type 16 E5 protein induces expression of beta interferon through interferon regulatory factor 1 in human keratinocytes. J Virol 2011, 85:5070-5080.

124. Schiller JT, Vass WC, Vousdan KH, Lowy DR: The E5 open reading frame of bovine papillomavirus type 1 encodes a transforming gene. J Virol 1986, 57:1-6.

125. Schlegel R, Wade-Glass M, Rabson MS, Yang YC: The E5 transforming gene of bovine papillomavirus encodes a small hydrophobic polypeptide. Science 1986, 233:464-467.

126. Burkhardt A, DiMaio D, Schlegel R: Genetic and biochemical definition of the bovine papillomavirus E5 transforming protein. EMBO J 1987, 8:2381-2385.

127. Pennie WD, Grindlay GJ, Cairney M, Campo MS: Analysis of the transforming functions of bovine papillomavirus type 4. Virology 1993 19:614-620.

128. Marchetti B, Ashrafi GH, Tsirimonaki E, O'Brien PM, Campo MS: The bovine papillomavirus oncoprotein E5 retains MHC class I molecole in the Golgi apparatus and prevents their transport to the cell surface. Oncogene 2002, 21:7808-7816.

129. King G, Oates J, Patel D, van den Berg HA, Dixon AM: Towards a structural understanding of the smallest known oncoprotein: Investigation of the bovine papillomavirus E5 protein using solution-state NMR. Biochim Biophys Acta 2011, 1808:1943-1501.

130. Windisch D, Hoffmann S, Afonin S, Vollmer S, Benamira S, Langer B, Bürck J, Muhle-Goll C, Ulrich AS: Structural role of the conserved cysteines in the dimerization of the viral transmembrane oncoprotein E5. Biophys $J$ 2010, 99:1764-1772.

131. Oates J, Hicks M, Dafforn TR, DiMaio D, Dixon AM: In vitro dimerization of the bovine papillomavirus $\mathrm{E} 5$ protein transmembrane domain. Biochemistry 2008, 47:8985-8992.

132. Campo MS, Moar MH, Jarret WFH, Laird HM: A new papillomavirus associated with alimentary cancer in cattle. Nature 1980, 286:180-182.

133. Bergman P, Ustav M, Sedman J, Moreno-Lopéz J, Vennström B, Pettersson U: The E5 gene of bovine papillomavirus type 1 is sufficient for complete oncogenic transformation of mouse fibroblasts. Oncogene 1988, 2:453-459.

134. Petti LM, Ray FA: Transformation of mortal human fibroblasts and activation of a growth inhibitory pathway by the bovine papillomavirus E5 oncoprotein. Cell growth differ 2000, 11:395-408.

135. O'Brien V, Ashrafi GH, Grindlay GJ, Anderson R, Campo MS: A Mutational Analysis of the Transforming Functions of the E8 Protein of Bovine Papillomavirus Type 4. Virology 1999, 255:385-394.

136. Tsirimonaki E, Ullah R, Marchetti B, Ashrafi GH, McGarry L, Ozanne B, Campo MS: Similarities and differences between the E5 oncoproteins of bovine papillomaviruses type 1 and type 4: cytoskeleton, motility and invasiveness in E5-transformed bovine and mouse cells. Virus Res 2006, 115:158-168.

137. Horwitz BH, Settleman J, Prakash SS, DiMaio D: Structure, activity, and regulation of the bovine papillomavirus E5 gene and its transforming protein product. Curr Top Microbiol Immunol 1989, 144:143-151.

138. Petti L, Nilson LA, DiMaio D: Activation of the platelet-derived growth factor receptor by the bovine papillomavirus E5 transforming protein. EMBO J 1991, 10:845-855.

139. Nilson LA, DiMaio D: Platelet-derived growth factor receptor can mediate tumorigenic transformation by the bovine papillomavirus E5 protein. Mol Cell Biol 1993, 13:4137-4145.

140. Goldstein DJ, Li W, Wang LM: The bovine papillomavirus type 1 E5 transforming protein specifically binds and activates the beta-type 
receptor for the platelet-derived growth factor but not other related tyrosine kinase-containing receptors to induce cellular transformation. Virol 1994, 68:4432-4441.

141. Drummond-Barbosa DA, Vaillancourt RR, Kazlauskas A, DiMaio D: Ligandindependent activation of the platelet-derived growth factor beta receptor: requirements for bovine papillomavirus E5-induced mitogenic signalling. Mol Cell Biol 1995, 15:2570-2581.

142. Cohen BD, Goldstein DJ, Rutledge L, Vass WC, Lowy DR, Schlegel R, Schiller JT: Transformation-specific interaction of the bovine papillomavirus E5 oncoprotein with the platelet-derived growth factor receptor transmembrane domain and the epidermal growth factor receptor cytoplasmic domain. J Virol 1993, 67:5303-5311.

143. Petti L, DiMaio D: Stable association between the bovine papillomavirus E5 transforming protein and activated platelet-derived growth factor receptor in transformed mouse cells. Proc Natl Acad Sci USA 1992, 89:6736-6740

144. Petti L, DiMaio D: Specific interaction between the bovine papillomavirus E5 transforming protein and the beta receptor for platelet-derived growth factor in stably transformed and acutely transfected cells. J Virol 1994, 68:3582-3592.

145. Klein O, Kegler-Ebo D, Su J, Smith S, DiMaio D: The bovine papillomavirus E5 protein requires a juxtamembrane negative charge for activation of the platelet-derived growth factor beta receptor and transformation of C127 cells. J Virol 1999, 73:3264-3272.

146. Lai CC, Edwards AP, DiMaio D: Productive interaction between transmembrane mutants of the bovine papillomavirus E5 protein and the platelet-derived growth factor beta receptor. J Virol 2005, 79:1924-1929.

147. Goldstein DJ, Andresson T, Sparkowski JJ, Schlegel R: The BPV-1 E5 protein, the $16 \mathrm{kDa}$ membrane pore-forming protein and the PDGF receptor exist in a complex that is dependent on hydrophobic transmembrane interactions. EMBO J 1992, 11:4851-4859.

148. Klein O, Polack GW, Surti T, Kegler-Ebo D, Smith SO, DiMaio D: Role of glutamine 17 of the bovine papillomavirus E5 protein in platelet-derived growth factor beta receptor activation and cell transformation. $J$ Virol 1998, 72:8921-8932.

149. Surti T, Klein O, Aschheim K, DiMaio D, Smith SO: Structural models of the bovine papillomavirus E5 protein. Proteins 1998, 33:601-612.

150. Kulke R, DiMaio D: Biological properties of the deer papillomavirus E5 gene in mouse C127 cells: growth transformation, induction of DNA synthesis, and activation of the platelet-derived growth factor receptor. J Virol 1991, 65:4943-4949.

151. Horwitz BH, Burkhardt AL, Schlegel R, DiMaio D: 44-amino-acid E5 transforming protein of bovine papillomavirus requires a hydrophobic core and specific carboxyl-terminal amino acids. Mol Cell Biol 1988, 8:4071-4078

152. Horwitz BH, Weinstat DL, DiMaio D: Transforming activity of a 16-aminoacid segment of the bovine papillomavirus E5 protein linked to random sequences of hydrophobic amino acids. J Virol 1989, 63:4515-4519.

153. Meyer AN, Xu Y-F, Webster MK, Smith AE, Donoghue DJ: Cellular transformation by a transmembrane peptide: structural requirements for the bovine papillomavirus E5 oncoprotein. Proc Natl Acad Sci USA 1994, 91:4634-4638.

154. Kulke R, Horwitz BH, Zibello T, DiMaio D: The central hydrophobic domain of the bovine papillomavirus E5 transforming protein can be functionally replaced by many hydrophobic amino acid sequences containing a glutamine. J Virol 1992, 66:505-511.

155. Mattoon D, Gupta K, Doyon J, Loll PJ, DiMaio D: Identification of the transmembrane dimer interface of the bovine papillomavirus E5 protein. Oncogene 2001, 20:3824-3834.

156. Nappi VM, Petti LM: Multiple transmembrane amino acid requirements suggest a highly specific interaction between the bovine papillomavirus E5 oncoprotein and the platelet-derived growth factor beta receptor. J Virol 2002, 76:7976-7986.

157. Nappi VM, Schaefer JA, Petti LM: Molecular examination of the transmembrane requirements of the platelet-derived growth factor beta receptor for a productive interaction with the bovine papillomavirus E5 oncoprotein. J Biol Chem 2002, 277:47149-47159.

158. Petti LM, Reddy V, Smith SO, DiMaio D: Identification of amino acids in the transmembrane and juxtamembrane domains of the platelet- derived growth factor receptor required for productive interaction with the bovine papillomavirus E5 protein. J Virol 1997, 71:7318-7327.

159. Staebler A, Pierce JH, Brazinski S Heidaran MA, Li W, Schlegel R, Goldstein DJ: Mutational analysis of the beta-type platelet-derived growth factor receptor defines the site of interaction with the bovine papillomavirus type 1 E5 transforming protein. J Virol 1995, 69:6507-6517.

160. Corteggio A, Urraro C, Roperto S, Roperto F, Borzacchiello G: Phosphatidylinositol-3-kinase-AKT pathway, phospho-JUN and phosphoJNK expression in spontaneously arising bovine urinary bladder tumours. J Comp Pathol 2010, 143:173-178.

161. Corteggio A, Di Geronimo O, Roperto S, Roperto F, Borzacchiello G: Activated platelet-derived growth factor $\beta$ receptor and Ras-mitogenactivated protein kinase pathway in natural bovine urinary bladder carcinomas. Vet J 2011.

162. Petti LM, Ricciardi EC, Page HJ, Porter KA: Transforming signals resulting from sustained activation of the PDGFbeta receptor in mortal human fibroblasts. J Cell Sci 2008, 121:1172-1182.

163. Suprynowicz FA, Baege A, Sunitha I, Schlegel R: c-Src activation by the E5 oncoprotein enables transformation independently of PDGF receptor activation. Oncogene 2002, 21:1695-1706.

164. Suprynowicz FA, Sparkowski J, Baege A, Schlegel R: E5 oncoprotein mutants activate phosphoinositide 3-kinase independently of plateletderived growth factor receptor activation. J Biol Chem 2000, 275:5111-5119.

165. Grindlay GJ, Campo MS, O'Brien V: Transactivation of the cyclin A promoter by bovine papillomavirus type 4 E5 protein. Virus Res 2005, 108:29-38.

166. O'Brien V, Campo MS: BPV-4 E8 transforms NIH3T3 cells, up-regulates cyclin A and cyclin A-associated kinase activity and de-regulates expression of the cdk inhibitor p27Kip1. Oncogene 1998, 17:293-301.

167. O'Brien V, Grindlay GJ, Campo MS: Cell transformation by the E5/E8 protein of bovine papillomavirus type 4. p27(Kip1), Elevated through increased protein synthesis is sequestered by cyclin D1-CDK4 complexes. J Biol Chem 2001, 276:33861-33868.

168. Zago M, Campo MS, O'Brien V: Cyclin A expression and growth in suspension can be uncoupled from p27 deregulation and extracellular signal-regulated kinase activity in cells transformed by bovine papillomavirus type 4 E5. J Gen Virol 2004, 85:3585-3595.

169. Ashrafi GH, Tsirimonaki E, Marchetti B, O'Brien PM, Sibbet GJ, Andrew L, Campo MS: Down-regulation of MHC class I by bovine papillomavirus E5 oncoproteins. Oncogene 2002, 2:248-259.

170. Ashrafi GH, Brown DR, Fife KH, Campo MS: Down-regulation of MHC class I is a property common to papillomavirus E5 proteins. Virus Res 2006, 120:208-211.

171. Faccini AM, Cairney M, Ashrafi GH, Finbow ME, Campo MS, Pitts JD: The bovine papillomavirus type 4 E8 protein binds to ductin and causes loss of gap junctional intercellular communication in primary fibroblasts. $J$ Virol 1996, 70:9041-9045.

172. Andresson T, Sparkowski J, Goldstein DJ, Schlegel R: Vacuolar H(+)-ATPase mutants transform cells and define a binding site for the papillomavirus E5 oncoprotein. J Biol Chem 1995, 270:6830-6837.

173. Ashrafi GH, Pitts JD, Faccini AM, McLean P, O'Brien V, Finbow ME, Campo S: Binding of bovine papillomavirus type 4 E8 to ductin (16K proteolipid), down-regulation of gap junction intercellular communication and full cell transformation are independent events. $J$ Gen Virol 2000, 81:689-694.

174. Roperto S, De Tullio R, Raso C, Stifanese R, Russo V, Gaspari M, Borzacchiello G, Averna M, Paciello O, Cuda G, Roperto F: Calpain3 is espresse in a proteolitically active form in papillomavirus-associated urothelial tumours of the urinary bladder in cattle. PLos One 2010, 5: e10299.

175. Kim MK, Kim HS, Kim SH, Oh JM, Han JY, Lim JM, Juhnn YS, Song YS: Human papillomavirus type 16 E5 oncoprotein as a new target for cervical cancer treatment. Biochem Pharmacol 2010, 80:1930-1935.

176. Liu DW, Tsao YP, Hsieh CH, Hsieh JT, Kung JT, Chiang CL, Huang SJ, Chen SL: Induction of CD8 T Cells by Vaccination with Recombinant Adenovirus Expressing Human Papillomavirus Type 16 E5 Gene Reduces Tumor Growth. J Virol 2000, 74:9083-9089.

177. Chen YF, Lin CW, Tsao YP, Chen SL: Cytotoxic-T-lymphocyte human papillomavirus type 16 E5 peptide with $\mathrm{CpG}$-oligodeoxynucleotide can eliminate tumor growth in C57BL/6 mice. J Virol 2004, 78:1333-1343. 
178. Lorenzon L, Mazzetta F, Venuti A, Frega A, Torrisi MR, French D: In vivo HPV 16 E5 mRNA: Expression pattern in patients with squamous intraepithelial lesions of the cervix. J Clin Virol 2011, 52:79-83.

179. Wang W, Sima N, Kong D, Luo A, Gao Q, Liao S, Liao S, Li W, Han L, Wang J, Wang S, Lu Y, Wang D, Xu G, Zhou J, Meng L, Ma D: Selective targeting ofHPV-16 E6/E7 in cervical cancer cells with a potent oncolytic adenovirus and its enhanced effect with radiotherapy in vitro and vivo. Cancer Lett 2010, 291:67-75.

180. Jonson AL, Rogers LM, Ramakrishnan S, Downs LS Jr: Gene silencing with siRNA targeting E6/E7 as a therapeutic intervention in a mouse model of cervical cancer. Gynecol Oncol 2008, 111:356-364.

181. Raghava S, Giorda KM, Romano FB, Heuck AP, Hebert DN: The SV40 late protein VP4 is a viroporin that forms pores to disrupt membranes for viral release. PLoS Pathog 2011, 7:e1002116.

182. Maufort JP, Shai A, Pitot HC, Lambert PF: A role for HPV16 E5 in cervical carcinogenesis. Cancer Res 2010, 70:2924-2931.

183. Schwarz E, Freese UK, Gissmann L, Mayer W, Roggenbuck B, Stremlau A, zur Hausen $\mathrm{H}$ : Structure and transcription of human papillomavirus sequences in cervical carcinoma cells. Nature 1985, 314:111-114.

184. Borzacchiello G, Roperto F, Campo MS, Venuti A: 1st International Workshop on Papillomavirus E5 Oncogene-A report. Virology 2010, 408:135-137.

doi:10.1186/1476-4598-10-140

Cite this article as: Venuti et al:: Papillomavirus E5: the smallest oncoprotein with many functions. Molecular Cancer 2011 10:140.

\section{Submit your next manuscript to BioMed Central} and take full advantage of:

- Convenient online submission

- Thorough peer review

- No space constraints or color figure charges

- Immediate publication on acceptance

- Inclusion in PubMed, CAS, Scopus and Google Scholar

- Research which is freely available for redistribution

Submit your manuscript at www.biomedcentral.com/submit
C Biomed Central 